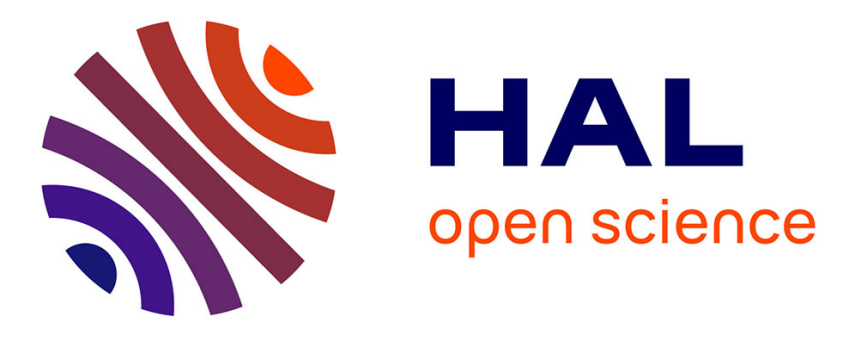

\title{
Pyrrolizidine Alkaloids in Honey: Comparison of analytical methods
}

Till Beuerle, Michael Kempf, Maximilian Wittig, Annika Reinhard, Katharina von Der Ohe, Tjeerd Blacquière, Kurt-Peter Raezke, Reinhard Michel, Peter

Schreier

\section{To cite this version:}

Till Beuerle, Michael Kempf, Maximilian Wittig, Annika Reinhard, Katharina von Der Ohe, et al.. Pyrrolizidine Alkaloids in Honey: Comparison of analytical methods. Food Additives and Contaminants, 2010, pp.1. 10.1080/19440049.2010.521772 . hal-00641195

\section{HAL Id: hal-00641195 \\ https://hal.science/hal-00641195}

Submitted on 15 Nov 2011

HAL is a multi-disciplinary open access archive for the deposit and dissemination of scientific research documents, whether they are published or not. The documents may come from teaching and research institutions in France or abroad, or from public or private research centers.
L'archive ouverte pluridisciplinaire $\mathbf{H A L}$, est destinée au dépôt et à la diffusion de documents scientifiques de niveau recherche, publiés ou non, émanant des établissements d'enseignement et de recherche français ou étrangers, des laboratoires publics ou privés. 


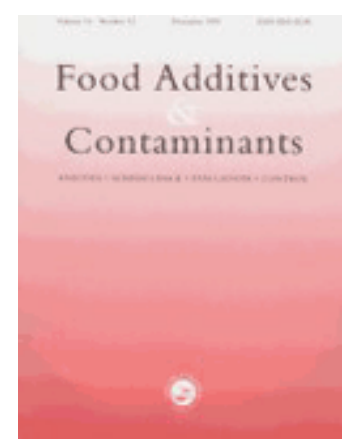

\section{Pyrrolizidine Alkaloids in Honey: Comparison of analytical methods}

\begin{tabular}{|r|l|}
\hline Journal: & Food Additives and Contaminants \\
\hline Manuscript ID: & TFAC-2010-147.R2 \\
\hline Manuscript Type: & Original Research Paper \\
\hline Duthor: & 30-Aug-2010 \\
\hline Complete List of Authors: & $\begin{array}{l}\text { Beuerle, Till; TU Braunschweig, Institut f. Pharmazeutische Biologie } \\
\text { Kempf, Michael } \\
\text { Wittig, Maximilian } \\
\text { Reinhard, Annika } \\
\text { von der Ohe, Katharina } \\
\text { Blacquière, Tjeerd } \\
\text { Raezke, Kurt-Peter } \\
\text { Michel, Reinhard } \\
\text { Schreier, Peter }\end{array}$ \\
\hline Methods/Techniques: & $\begin{array}{l}\text { Chromatography - GC/MS, Chromatography - LC/MS, Risk } \\
\text { assessment }\end{array}$ \\
\hline Additives/Contaminants: & Natural toxicants - alkaloids \\
\hline Food Types: & Honey \\
\hline
\end{tabular}

\section{SCHOLARONE ${ }^{\text {M }}$ Manuscripts}




\section{Keywords:}

2 Food safety, honey, pyrrolizidine alkaloids, pyrrolizidine $\mathrm{N}$-oxides; gas chromatography 3 mass spectrometry (GC-MS), high performance liquid chromatography mass spectrometry 4 (HPLC-MS), Jacobeae vulgaris (syn. Senecio jacobeae, tansy ragwort), Echium spp., 5 Eupatorium spp., analytical methods

8 Abbreviations:

9 GC-EI-MS (SIM), gas chromatography electron ionization mass spectrometry operated in 10 the selected ion monitoring mode; GC-MS, gas chromatography-mass spectrometry; 11 HRGC-EI-MS (SIM), high resolution gas chromatography electron ionization mass 12 spectrometry operated in the selected ion monitoring mode; HRGC-MS, high resolution 13 gas chromatography-mass spectrometry; HPLC-MS, high-performance liquid 14 chromatography-mass spectrometry; HPLC-MS-MS, high-performance liquid 15 chromatography-tandem mass spectrometry; LC-ESI-MS, liquid chromatography 16 electrospray ionization mass spectrometry; LC-MS, liquid chromatography-mass 17 spectrometry; LC-MS-MS, liquid chromatography-tandem mass spectrometry; LLE, 18 continuous liquid-liquid extraction; LOQ, limit of quantification; MSTFA, N-Methyl- $N$ 19 (trimethylsilyl)trifluoroacetamide; PA, pyrrolizidine alkaloid; PANOs, pyrrolizidine alkaloid $\mathrm{N}$ 20 oxides; RSD, relative standard deviation; SD, standard deviation; $\mathrm{S} / \mathrm{N}$, signal-to-noise 21 ratio; SPE, solid phase extraction; SCX, strong cation exchange; SIM, selected ion 22 monitoring; TMS, trimethylsilyl group. 


\section{Introduction}

2 Pyrrolizidine alkaloids (PAs) are a group of constitutively expressed toxic plant defense 3 compounds found in an estimate of 6000 flowering plants world wide (Stegelmeier et al.

4 1999; Roeder 2000). These plants generally belong to one of four plant families within the

5 angiopserms: the Asteraceae (tribes Senecioneae and Eupatorieae), the Boraginaceae,

6 the Apocynaceae and the genus Crotalaria within the Fabaceae (Hartmann and Witte 7 1995).

8 In the past decades a multitude of biological cross connections involving PAs were 9 revealed. The effects and/or impacts of PAs range from deterrence, acute toxicity and 10 genotoxicity to adaptation, dependence or profitable use by specialized herbivores and on 11 to utilization of PAs in propagation and/or pheromone chemistry (Hartmann and Witte 12 1995). The structural diversity of $400+$ known PAs and the broad range of polarity typically 13 caused by the co-existence of tertiary PAs and PA-N-oxides (PANOs) represent a 14 particular analytical challenge. As a consequence, a large variety of different extraction 15 and concentration procedures, as well as analytical methods were developed over the 16 years (for review see, Mattocks 1986; Rizk 1991). An update, taking into account the 17 increasing importance of high-performance liquid chromatography-mass spectrometry 18 (HPLC-MS) techniques, was published recently (Crews et al. 2010).

19 However, returning to honey, PAs were frequently detected throughout the last 30 years 20 (for review see, Kempf et al. 2010a). Earlier studies were focused more or less on certain 21 honeys derived from known or suspected PA-plants. Hence, only a clearly pre-defined set 22 of PAs that needed to be considered. Recently, two studies were conducted on retail 23 honey with unknown history and/or origin (VWA 2007; Kempf et al. 2008). Both studies 24 pursued individual approaches and methodologies to measure low ppb-levels of PA in 25 honey. While the first method represents a target HPLC-MS-MS approach and covered 11 26 PAs and PANOs reference compounds, the second method is a sum parameter method, 
1 that uses GC-MS to detect the common backbone of most toxic relevant 1,2-unsaturated 2 PAs.

3 So far, no commonly accepted method exists on how to analyze PA in honey. In 4 cooperation with Intertek Food Services GmbH (a laboratory specialized in food analysis) 5 a LC-ESI-MS-MS (liquid chromatography electrospray ionization mass spectrometry) 6 based method was established which was intended to be applied to analyze honey from all 7 over the world. In the interest of a better estimation of the potential of LC-MS-MS vs. GC8 MS sum parameter three sample sets of honey were analyzed with both methods.

9 The results for different sample sets are discussed with respect to pros and cons for both 10 methods. 


\section{$1 \quad$ Material and Methods}

\section{Chemicals and solvents}

3 All chemicals were of analytical reagent purity and purchased from Acros Organics (Geel, 4 Belgium), Fluka (Buchs, Switzerland), Merck (Darmstadt, Germany), Sigma-Aldrich 5 (Steinheim, Germany) and Roth (Karlsruhe, Germany). All solvents were of HPLC grade 6 purity or redistilled before use.

\section{Reference materials}

9 For the determination of PAs in honey by LC-MS analysis the reference materials 10 echimidine, heliotrine, lasiocarpine, lycopsamine, monocrotaline, retrorsine, senecionine, 11 seneciphylline and senkirkine (Figure 1) were obtained from Phytolab GmbH \& Co. KG, 12 Germany. Isoproturone-d6 (internal standard) was obtained from Dr. Ehrenstorfer GmbH, 13 Germany. The $\mathrm{N}$-oxides of echimidine, heliotrine, lycopsamine, monocrotaline, retrorsine, 14 senecionine and seneciphylline were chemically synthesized and purified by a standard 15 method (Cymerman Craig and Purushothaman 1970). Stock solutions (10 mg/L) were 16 prepared in methanol.

17 To evaluate the GC-MS sum parameter method six PAs (Figure 1), monocrotaline (Sigma18 Aldrich, Steinheim, Germany), senecionine (Roth, Karlsruhe, Germany), seneciphylline 19 (Roth, Karlsruhe, Germany), senkirkine (Roth, Karlsruhe, Germany), heliotrine (Latoxan, 20 Valence, France) and retrorsine (Sigma-Aldrich, Steinheim, Germany) were purchased. 21 PAs and PANOs mixtures from S. vernalis were applied as previously described in Kempf 22 et al. (2008).

24 GC-MS sum parameter method

25 The applied method was described in detail previously (Kempf et al. 2008). In all samples, 26 except sample set C, $20 \mathrm{~g}$ of honey were used per work-up. Due to the high PA-contents 
1 measured in sample set $\mathrm{C}$, the sample weight was reduced for these samples to $5 \mathrm{~g}$ of 2 honey per work-up, to fit into the calibrated range. The sequence of individual steps is 3 summarized in a flow diagram (Figure 2).

4 GC-MS was carried out with a Fisons Instruments GC 8060 (Thermo Electron, Dreieich,

5 Germany) gas chromatograph with split/splitless injection $\left(220^{\circ} \mathrm{C} / 1: 20\right)$ directly coupled to

6 a Fisons Instruments MD 800 mass spectrometer (Thermo Electron, Dreieich, Germany) 7 essentially as described in Kempf et al. 2008.

8 Standard controlled relative quantification with heliotridine (originated from $2 \mu \mathrm{g}$ heliotrine 9 per sample) as internal standard was performed by HRGC-MS under the above mentioned 10 conditions. Linear retention indices were 1600 and 1632 for di-TMS-retronecine and the 11 standard di-TMS-heliotridine, respectively. Integration of peak area counts in EI-MS SIM12 mode $(\mathrm{m} / \mathrm{z} 93,183$ and 299) was carried out. The relative intensities of these analytical 13 ions to each other were used as tool for the determination of the purity of the 14 corresponding peak. These values were compared to values obtained from authentic 15 reference compounds; variances of $<10 \%$ were tolerated. No extraction/response factors $16 \quad(F=1.0)$ were considered. The data obtained was finally calculated into retronecine 17 equivalents as previously described in Kempf et al. 2008.

\section{LC-ESI-MS-MS method}

20 Samples were analyzed using a Thermo Fisher Surveyor autosampler and liquid 21 chromatography system coupled to a triple quadrupole mass spectrometer TSQ Quantum 22 Ultra (ThermoFisher, San Jose, CA, USA). Samples were injected onto a $150 \times 2.1 \mathrm{~mm}$, $235 \mu \mathrm{m}$ Thermo Hypersil Gold reversed-phase column (ThermoFisher, San Jose, CA, USA). 24 The sample preparation was realized by liquid-liquid extraction followed by online solid25 phase extraction (online SPE) for cleanup. For on-line SPE clean-up the SPE2000 module 26 (Intertek Food Sevices, Bremen, Germany) was used. The module includes a pump and 
1 two 6-port swichting valves. The PAs are trapped on an on-line SPE-cartridge $(10 \times 4 \mathrm{~mm}$,

$25 \mu \mathrm{m}$ Thermo Hypersil Gold ,ThermoFisher, San Jose, CA, USA). Subsequently, the 3 column is washed with water to rinse and minimize matrix compounds. The analytes are 4 eluted in back-flush direction to the LC-MS for detection. The cartridge is reconditioned for 5 the next sample afterwards. The detailed programming of the SPE2000 module is added 6 to the supplement.

7 The PAs were eluted from the column with a gradient flow $(0.2 \mathrm{~mL} / \mathrm{min})$ of $0.1 \%$ glacial 8 acetic acid in water (mobile phase A) and $0.1 \%$ glacial acetic acid in methanol (mobile

9 phase B). The gradient was held at $90 \%$ mobile phase A for 2 min before being ramped 10 down to $10 \%$ over $8 \mathrm{~min}$. This condition for elution was held for $5 \mathrm{~min}$. The gradient was 11 set back to start conditions and re-equilibrated for $5 \mathrm{~min}$ in preparation for the next sample 12 injection.

13 The sample preparation is based on the QuEChERS method for determination of 14 pesticides in food matrices (Anastassiades et al. 2003). All honey samples were spiked 15 with the internal standard isoproturone-d6 $\left(100 \mu \mathrm{g} \mathrm{kg}^{-1}\right)$ before sample preparation. The 16 honey samples $(1 \mathrm{~g})$ were diluted with water $(4 \mathrm{~mL})$ and homogenized for $5 \min .1 .3 \mathrm{~g}$ 17 QuEChERS-salt $\left(0.8 \mathrm{~g} \mathrm{MgSO}_{4} ; 0.2 \mathrm{~g} \mathrm{NaCl} ; 0.1 \mathrm{~g}\right.$ citric acid disodium salt sesquihydrate; $18 \quad 0.2 \mathrm{~g}$ sodium citrate dihydrate) and $4 \mathrm{~mL}$ acetonitrile were added, extracted for $15 \mathrm{~min}$ and 19 centrifuged at $10000 \mathrm{~g}$ for $6 \mathrm{~min} .3 .5 \mathrm{~mL}$ of the upper phase was transferred to another 12 $20 \mathrm{~mL}$ centrifugation tube and $0.5 \mathrm{~g} \mathrm{MgSO}_{4}$ was added. After homogenization for $5 \mathrm{~min}$ and 21 centrifugation at $10000 \mathrm{~g}$ for $6 \mathrm{~min} 3 \mathrm{~mL}$ of the supernatant was transferred to another tube 22 and evaporated to dryness. The residue was reconstituted with methanol/water solution 23 (1 mL) containing $0.08 \%$ glacial acetic acid in water $(900 \mu \mathrm{L})$ and methanol $(100 \mu \mathrm{L}) .100$ $24 \mu \mathrm{L}$ were analyzed using LC-online-SPE-MS. For the cleanup step by online-SPE a $10 \mathrm{x}$ $254 \mathrm{~mm}, 5 \mu \mathrm{m}$ Thermo Hypersil Gold (ThermoFisher, San Jose, CA, USA) column was used. 26 An overview of the individual steps in given in Figure 2. 
1 Mass spectrometric data were collected in the positive heated-ESI-mode (electrospray

2 ionization). The capillary temperature was $300^{\circ} \mathrm{C}$ at a spray voltage of $5.8 \mathrm{kV}$. The sheath 3 gas flow was 25 arb units and the aux gas 5 arb units, respectively. The protonated

4 molecules $[\mathrm{M}+\mathrm{H}]^{+}$of PAs and corresponding $\mathrm{N}$-oxides were chosen as the parent ions for 5 fragmentation (for more details see supplement). At least 2 product ions of every PA were 6 determined for identification in accordance with the European commission decision 7 2002/657/EC (European Commission 2002). For quantification the samples were calibrated against matrix-matched standards (polyfloral honey). Extraction losses were corrected by an internal standard isoproturone-d6. Due to the lack of certified stableisotope labeled PA-analogues this is an first approach for quality control. For validation a blank polyfloral honey was fortified with PAs and the internal standard. This was done in 126 -fold at three levels $\left(1.0 \mu \mathrm{g} \mathrm{kg}^{-1}, 1.5 \mu \mathrm{g} \mathrm{kg}^{-1}\right.$ and $\left.2.0 \mu \mathrm{g} \mathrm{kg}^{-1}\right)$ on three different days. 13 Together with control samples $\left(0 \mu \mathrm{gg}^{-1}\right)$, the fortified samples were processed using the 14 described method. To investigate the influence of different honey-matrices on the PA 15 determination, three typical honeys (acacia, polyfloral, honeydew) were analyzed (blank 16 and fortified with $1 \mu \mathrm{g} \mathrm{kg}^{-1}$ ). No matrix interference was observed at the specific retention 17 time of the analytes for all tested matrices. Moreover matrix-matched standards at $0.5 \mu \mathrm{g}$ $18 \mathrm{~kg}^{-1}, 1 \mu \mathrm{g} \mathrm{kg}^{-1}, 1.5 \mu \mathrm{g} \mathrm{kg}^{-1}, 2.0 \mu \mathrm{g} \mathrm{kg}^{-1}$ and $4.0 \mu \mathrm{g} \mathrm{kg}^{-1}(\mathrm{n}=6)$ were analyzed to verify the 19 linearity of response versus concentration. Recoveries and RSD (relative standard 20 deviation) were calculated at $1.0 \mu \mathrm{g} \mathrm{kg}^{-1}$, using the average of the $1.0 \mu \mathrm{g} \mathrm{kg}{ }^{-1}$ matrix21 matched standard $(\mathrm{n}=6)$. The limit of quantification $\left(\mathrm{S} / \mathrm{N}\right.$ 10:1) of $1 \mu \mathrm{g} \mathrm{kg}{ }^{-1}(1 \mathrm{ppb})$ can be 22 applied for all PAs except monocrotaline and monocrotaline- $\mathrm{N}$-oxide (50 ppb). Recoveries 23 range from $97.5 \%$ (echimidine- $N$-oxide) to $104.6 \%$ (lycopsamine- $N$-oxide) and the RSD 24 from $4.9 \%$ (heliotrine- $N$-oxide) to $38.8 \%$ (seneciphylline).

25 Furthermore the developed LC-MS method was successfully tested on matrices like bee pollen, milk products, PA-plants and feed. The sample preparation leads to clean sample 
1 extracts and therefore to reproducible results at low PA-levels $\left(1-10 \mu \mathrm{gg}^{-1}\right)$.

3 Retail honey samples

4 Pure Echium honeys $(\mathrm{n}=8)$, purchased via internet stores, were harvested in New Zealand 5 in season 2006 (sample set A). Sample set B consisted of a set of random raw honeys $6 \quad(n=8)$ which were imported to Germany in 2008.

8 Honey from J. vulgaris (sample set $C$ )

$9 \underline{2007}$

10 To harvest honey on a location with high abundance of $\mathrm{J}$. vulgaris colonies were prepared 11 and placed in two locations in the Netherlands, Planken Wambuis (close to Ede; PW2007) 12 and Sinderhoeve (Heelsum; SH2007), on June 13th, 2007. The colonies consisted of a 13 one storey hive with ten frames, of which seven to eight with brood, and with about 12-15 14 thousand bees. The two side frames consisted of empty, fresh foundation comb. The 15 colonies were provided with sugar dough on top of the hive.

16 At the location Sinderhoeve the field with $\mathrm{J}$. vulgaris was mown on July 10th. On both 17 locations honey was harvested on August 1st, 2007. At the location Sinderhoeve from both 18 of the colonies a full frame with sealed honey was harvested. At Planken Wambuis one 19 colony also produced a full frame with sealed honey, the other colony had only one frame 20 with a little honey. At the moment of harvest around the location Sinderhoeve hardly any 21 flowering J. vulgaris was left, some Asteraceae, white clover and some Brasicaceae 22 flowered. Also the heather started to flower. On Planken Wambuis only very few flowering 23 J. vulgaris plants were left. Other plants present in the area were thistle, some other 24 Asteraceae including Senecio inaequidens and heather.

$25 \underline{2008}$

26 Four locations in the Netherlands were set up: Groenendaal (south of Apeldoorn, 
1 GR2008): Planken Wambuis, Oud Reemst (Otterloo, PW2008); Reijerskamp (Wolfheze, 2 RK2008); Sinderhoeve, (SH2008). The colonies were similar to 2007, and were placed on 3 July 2 nd. On July 17 th it was observed that most of the colonies did not produce much 4 honey so far. On all locations in July honey bees have been observed visiting J. vulgaris 5 flowers. The same was still true on July 28th, at that time most of the J. vulgaris had 6 finished flowering, and the heather started flowering. Therefore on August 2nd the honey 7 samples were harvested from the colonies: not one fully sealed comb was found, so 8 sealed honey parts were cut from the frames as samples. About 110 to $350 \mathrm{~mL}$ of honey 9 per colony were harvested by pressing and further purified by sieving. A second sample, 10 after the honey flow of heather, was taken on October 2 nd. From most of the colonies a full 11 comb of honey could be harvested. Other available plants were Prunella, Myosotis, Crepis, 12 Matricaria, Cirsium, Achillea, Vicia, Trifolium, Cerastium, Hypericum, Epilobium and Viola. 13 After pressing the honey was sieved through a double honey sieve, and stored as 14 separate lots in Greiner tubes of $50 \mathrm{ml}$ in the freezer.

26 Sampling of pollen from honey and the determination of the botanical origin was performed 
1 by Standard Operation Procedure 95 from bees@wur (P.O. Box 16, 6700 AA Wageningen

2 Building 107, Droevendaalsesteeg 1, 6708 PB Wageningen The Netherlands). In this

3 procedure 10 grams of honey mixed with $20 \mathrm{~mL}$ demineralized water is centrifuged, and 4 the pellet is used to resuspend on microscopic slides, to which a droplet of 5 glycerol/gelatin/fuchsin is added and which is closed by a cover glass. A total of 500 pollen 6 grains was determined to the genus level, in some cases down to the species level, by 7 microscopic observation at a magnification of $400 x$. 
1 Results and Discussion

2 The GC-MS sum parameter method was already described in detail (Kempf et al. 2008; 3 Kempf et al. 2010a; Kempf et al. 2010b). Here, only a brief overview and a flow chart 4 (Figure 2) are given. All 1,2-unsaturated PAs of the retronecine-type (including the 5 corresponding $\mathrm{N}$-oxides) are converted into the common core structure retronecine which 6 is subsequently converted into di-TMS-retronecine and analyzed by GC-EI-MS (SIM).

7 Heliotrine is used as internal standard for quantification, resulting in di-TMS-heliotridine (a 8 diastereomere of di-TMS-retronecine) and was separated from its diastereomere on a 9 regular GC column. To reach a $\mathrm{LOQ}$ of $10 \mathrm{ppb}(\mathrm{S} / \mathrm{N}$ of 7:1) the work-up required $20 \mathrm{~g}$ of 10 honey, reduction of the $\mathrm{N}$-oxides and pre-concentration by SPE on SCX material. A 11 number of PA-plants are described as potential sources for PA-contamination of honey 12 (Edgar et al. 2002). However this method does not require any information about the 13 possible PA-plant sources beforehand to conduct the analysis and the result is expressed 14 in retronecine equivalents.

15 To establish a new effective and problem adequate LC-MS method for the general PA 16 analysis in honey we first had to identify the PA-structures that are most likely to appear in 17 honey. To achive this, several hundred pollen analysis pollen results that were obtained by 18 routine controls of raw honeys imported to Germany during the period 2007-2009 (at 19 Intertek Food Services) were evaluated for the most frequent PA-plants. The result is 20 summarized in Table 1. As second step, literature and in-house databases of PA-plants 21 were analyzed to identify commercially available marker-PAs that reflect the relevant PA22 plants (Table 1). During this study and to this day only a limited number of PA compounds 23 was/is available (Figure 1) as certified standards while no commercial source for PANOs 24 was available. The corresponding PANOs were obtained from the tertiary PA-references 25 by standard chemical conversion (Cymerman Craig and Purushothaman 1970). For most 26 of the known "trouble makers" in honey at least one marker PA could be assigned (Table 
1 1), but it needs to be considered that it is in the nature of things that the determination of

2 individual PAs with a rather limited set of reference compounds necessarily risks that not

3 included PAs will be overlooked. However, this approach was tailored specifically to honey

4 and should reliably indicate a PA-contamination in honey but quantitative analysis results

5 can only be assigned to the target compounds.

6 Three distinct sample sets were analyzed with both methods. To compare both methods, it

7 is necessary to consider the molecular weight of each PA and convert the results of the

8 single PA-determination by LC-MS into retronecine equivalents to compare it to the result

9 obtained from the GC-MS method (the original data, pollen analysis results etc. for all

10 samples is supplied as supplemental data).

11 The first sample set (set A) was composed of monofloral honeys from New Zealand. The 12 pollen analysis of all samples revealed $61 \%$ to $80 \%$ Echium pollen. Earlier studies 13 demonstrated that honey from Echium spp. is dominated by the occurrence of echimidine 14 (Beales et al. 2004). Figure 3 summarizes the results for both methods. The structural 15 information of the initial PAs is lost in the GC-MS sum parameter method, but in this study 16 we were able to retrace this information from the LC-MS approach. Therefore, the most 17 prominent PA was echimidine (up to $99 \%$ ) accompanied by small amounts (1\% to $2 \%$ ) of 18 echimidine $\mathrm{N}$-oxide and trace amounts of a lycopsamine-type PA (less than $0.2 \%$ ). In 19 addition, Figure 3 clearly demonstrates a good correlation for both methods for Echium20 honeys, and suggests that the determination of echimidine/echimidine- $N$-oxide seems to 21 reflect to a high degree the PA content of Echium-honey. Both, E. plantagineum 22 (Patersons's curse) and E. vulgare (Viper's bugloss) are a very attractive nectar and pollen 23 source for honey bees (Somerville 2005). Pollen analysis suggests Echium-occurrence in 24 major honey exporting regions like Australia/New Zealand, South America and southern 25 Europe (Kempf et al. 2008; Kempf et al. 2010a; Kempf et al. 2010b). Hence, it is absolutely 26 essential to include echimidine/echimidine- $N$-oxide in a target analysis approach for the 
1 determination of PAs in honey. Unfortunately however, the availability of echimidine is

2 limited at the present time and the corresponding $\mathrm{N}$-oxide was not available as certified 3 reference material.

4 The second sample set (set B) consisted of eight randomly picked raw honeys which were 5 imported to Germany in 2008 (details see supplement). The quantitative result for both 6 methods is summarized in Figure 4. Again the obtained values (re-calculated in 7 retronecine equivalents) are quite similar. It was striking, that also samples without any 8 PAs, correlated for both methods, which proofed, that both methodologies worked reliable 9 in a yes/no determination of possible PA-contamination of honey. This time the individual 10 PA-pattern detected by the LC-MS method was characterized almost exclusively by 11 lycopsamine-type PAs (one sample also contained $2 \%$ lycopsamine-type- $\mathrm{N}$-oxide; and 12 another sample had in addition to lycopsamine-type PAs 3\% echimidine). In this context, 13 lycopsamin-type-PA is the sum of all possible stereoisomers, including indicine, 14 intermedine, lycopsamine, rinderine and echinatine. However, all five PAs are structurally 15 closely related diastereomeres, a similar retention behavior and mass spectrometric 16 response can be assumed and it seems reasonable to record them as sum of 17 lycopsamine-type PAs without complete structural assignment. The positive result for 18 sample B6 and B7 can be traced back to Eupatorium as floral source (see supplement). 19 Hence, the detection of lycopsamine-type PA is the logical consequence. In contrast, for 20 sample B2 only low amounts of Echium pollen were spotted (and are reflected in low 21 echimidine concentration $15 \mu^{-1} \mathrm{~kg}^{-1}$; retronecine equivalents) but at the same time high 22 amounts of lycopsamine were found as well (607 $\mathrm{g} \mathrm{kg}^{-1}$; retronecine equivalents). Given 23 the present knowledge, lycopsamine is usually not dominating in Echium spp.. Thus, the 24 result can be interpreted in three ways, either (i) pollen of a known PA-plant were 25 overlooked; or (ii) pollen was not represented in the honey; or (iii) most likely, our list of 26 forage plants is still incomplete but in this case the PA-pattern of the "unknown/not pollen 
1 represented" plant is dominated by lycopsamine. Up to this day, only lycopsamine is

2 available as reference compound at limited quantities and no commercial source for the 3 corresponding $\mathrm{N}$-oxide is available at the moment.

4 Special attention was given to samples (set C) from two consecutives seasons (2007 and 5 2008) which were obtained from consciously placed bee hives at sites with high 6 abundance of Jacobaea vulgaris (syn. Senecio jacobaea, tansy ragwort) in the 7 Netherlands. All four locations were located on rather poor sandy soils, in the Veluwe 8 region. The Veluwe is a Natural Park Area in the Netherlands, in which several formerly 9 agriculturally used fields are returned to nature conservation programs. Generally after a 10 few years of succession such fields are dominated by tansy ragwort. Many of these sites 11 consist of several tens of hectares. The sites Groenendaal and Planken Wambuis are in 12 the center of the park, the Sinderhoeve and Reijerskamp closer to the edges.

13 This was considered a worst case scenario, since it was tried to force the bees to forage 14 on tansy ragwort, which was the only abundant flowering species in these areas during 15 July. To obtain a more realistic impression of possible contamination of honey harvested by 16 bee keepers in this area, a second harvest from the same colonies was made at the 17 beginning of October 2008. This honey included the heather honey flow from August 18 typical for this region.

19 When honey was harvested in early August 2007 and 2008, it was found that the dominant 20 pollen species in the honey were from the Clusiaceae (Hypericum), Fagaceae (Castanea), 21 Brassicaceae (Sinapis), Fabaceae (Trifloium, Lotus, Medicago) and Ericaceae (Erica and 22 Calluna). The honey harvested on October 6th, 2008 was dominated by the Ericaceae 23 (Calluna), and in one case Liliaceae.

24 Set $\mathrm{C}$ showed a large variation of the detected PA-content of the individual honeys for 25 each method (see Figure 5). While the amount of PA-plant pollen was low in these honeys $26(0-6.3 \%)$ the total PA-amount in some cases reached extreme values (range: 0-13019 $\mu \mathrm{g}$ 
$1 \mathrm{~kg}^{-1}$; average 1261 or $76 \mu \mathrm{kg}^{-1}$ for GC-MS and LC-MS, respectively). In average theses

2 ragwort honeys showed PA levels that were 23 times higher than those found for retail 3 honeys and showed a contamination rate of $86 \%$ (compared to $9 \%$ contamination rate 4 recently found for retail honeys, Kempf et al. 2008). The small amount of ragwort pollen 5 found in those samples also suggests that pollen cannot be the only source of PA6 contamination in Senecio-honey. In fact, nectar has to contribute to reach those high 7 levels.

8 As a general rule, the total PA-amounts in the GC-MS sum parameter approach were 9 much higher (ranging from a factor of approximately 2 to 124; average factor of 17). 10 However, at second glance, the data also showed very important correlations. Namely, all 11 the samples that do not contain any or very small amounts of PA (below the detection limit 12 of the GC-MS approach) were the same in both approaches. This leads to assume, that 13 there was no false positive detection with either method and all positive samples 14 (considering the different detection limits for both methods) were also detected with both 15 approaches. Still, the strong discrepancy of the PA-positive samples needs some 16 explanation. For a number of reasons, we are quite confident that the values obtained with 17 the sum parameter approach are really representing the total amount of 1,2-unsaturated 18 PAs. First, as mentioned above PA-negative is negative in both approaches. Secondly, in 19 all other sample sets before we used $20 \mathrm{~g}$ of honey for the work-up, for set $\mathrm{C}$ honeys, only $205 \mathrm{~g}$ were used because the PA-content was too high for the calibrated range. Hence, false 21 positive results or matrix effects which might add to the total PA-amount should be rather 22 decreased than increased in this set. Another argument in favor for the correctness of the 23 sum parameter results comes from biosynthesis studies of several Senecio spp. There, the 24 primary and dominant formation of senecionine- $\mathrm{N}$-oxide was demonstrated in roots 25 (Hartmann and Toppel 1987; Toppel et al. 1987). Subsequently, senecionine- $N$-oxide gets 26 translocated via the phloem to the remaining plant organs (Hartmann et al. 1989). During 
1 this process several successive and simple transformations of the primary senecionine- $N$ -

2 oxide structure take place and result in a species, organ and individual specific PA3 bouquet (Hartmann and Dierich 1998). Several studies have demonstrated the existence

4 of different chemotypes for J. vulgaris (syn. S. jacobaea, tansy ragwort) (Witte et al. 1992;

5 Macel et al. 2004). Particularly the study from Witte et al. (1992) seems to be important

6 since it reports the results of more than hundred individual analyzed $\mathrm{J}$. vulgaris flower

7 heads. There, in any case senecionine and seneciphylline were generally not dominating,

8 usually they were detected in trace amounts or sometimes absent. Instead, the dominant

9 PAs in flower heads, depending on the chemotype, were jacobine or

10 erucifoline/acetylerucifoline. Thus, given the biosynthetic background, the sensitive LC-MS 11 target analysis of senecionine and seneciphylline will most likely detect a PA12 contamination of honey derived from tansy ragwort. But, it will necessarily fall short of the 13 real value since major PAs were not available as certified standards and therefore not 14 included in the target PA-list.

15 However, the LC-MS determination showed another distinct feature. While in the sample 16 sets $\mathrm{A}$ and $\mathrm{B}, \mathrm{PANO}$ were of no importance, in sample set $\mathrm{C}$, the $\mathrm{N}$-oxides of senecionine 17 and seneciphylline represented in average $50 \%$ (ranging from 0 to $89 \%$ ) of the total PA18 amount. The reasons remain entirely unknown, but it demonstrates that also PANOs need 19 to be addressed, either through reduction and determination as tertiary PA (like in the GC20 MS approach, see Figure 2) or by an individual detection as $N$-oxide in a LC-MS approach 21 which in turn would require reliable sources for authentic reference material.

22 In addition, no correlation could be found between the percentage $J$. vulgaris pollen in the 23 honey and the PA-content of the honey (see supplement). However, the duration of 24 S. vulgaris exposure is clearly reflected in the 2007 samples. There, the $\mathrm{SH} 2007$ samples 25 showed significant lower PA levels which can be explained by the mowing of the 26 S. vulgaris fields three weeks before harvest. 


\section{Conclusions and Summary}

3 The comparison of both methods for the determination of PAs in honey strongly correlated

4 for two reasons. First, both methods showed PA-positive results for the same samples and 5 in addition, considering the different detection limits for both methods, the reverse is also

6 true for detecting PA-free samples. However, a closer look at the different sample sets (A-

7 C) indicated that for honeys from plant sources where only limited reference compounds

8 are available, a targeted approach can lead to a significant underestimation of the true PA-

9 content (set C). The data presented here, shows the critical points of two different 10 approaches for the PA-determination in honey. As we learned during this study, both 11 methods have strong advantages and drawbacks that need to be considered. These are 12 categorized in a short tabular form in Table 2.

13 Finally, the choice of an appropriate method depends on many factors (time, costs, 14 validations, LOQs, man power, availability of reference compounds etc.) and it will still 15 need vivid discussions and improvements for both approaches until reliable and efficient 16 PA-determinations will be possible. Currently, and focused only on gain of information, 17 both methods supplement each other in perfect way, since valuable information, that was 18 necessarily lost in a sum parameter approach was complemented by the single PA19 determination.

20 In recent years increasing concerns were raised about fields and road sides which turned 21 yellow during summer due to the high abundance of tansy ragwort. By putting bee colonies 22 in areas covered with tansy ragwort the worst case was tested, and the contents of PAs 23 found were the highest reported in honeys so far and exceed the levels found in 24 commercially available honeys in an extreme case by a factor of more than 100 (sample $25 \mathrm{C} 1-1,13019 \mu \mathrm{g} \mathrm{kg}^{-1}$ compared to $120 \mathrm{\mu g} \mathrm{kg}^{-1}$; Kempf et al. 2008). Together with the results 26 obtained for Echium honeys, it seems evident that substantial efforts have to be made to 
1 prevent these honeys to enter the food chain. According to present knowledge, the most

2 effective way to address the problem would be the careful selection of the locations for the 3 bee hives (Reinhard et al. 2009). Since honey is traded globally the range of foraging 4 plants will be hard to predict for all geographic regions and from season to season. In such 5 circumstances, there seems to be no alternative to an analytical monitoring of honey. 


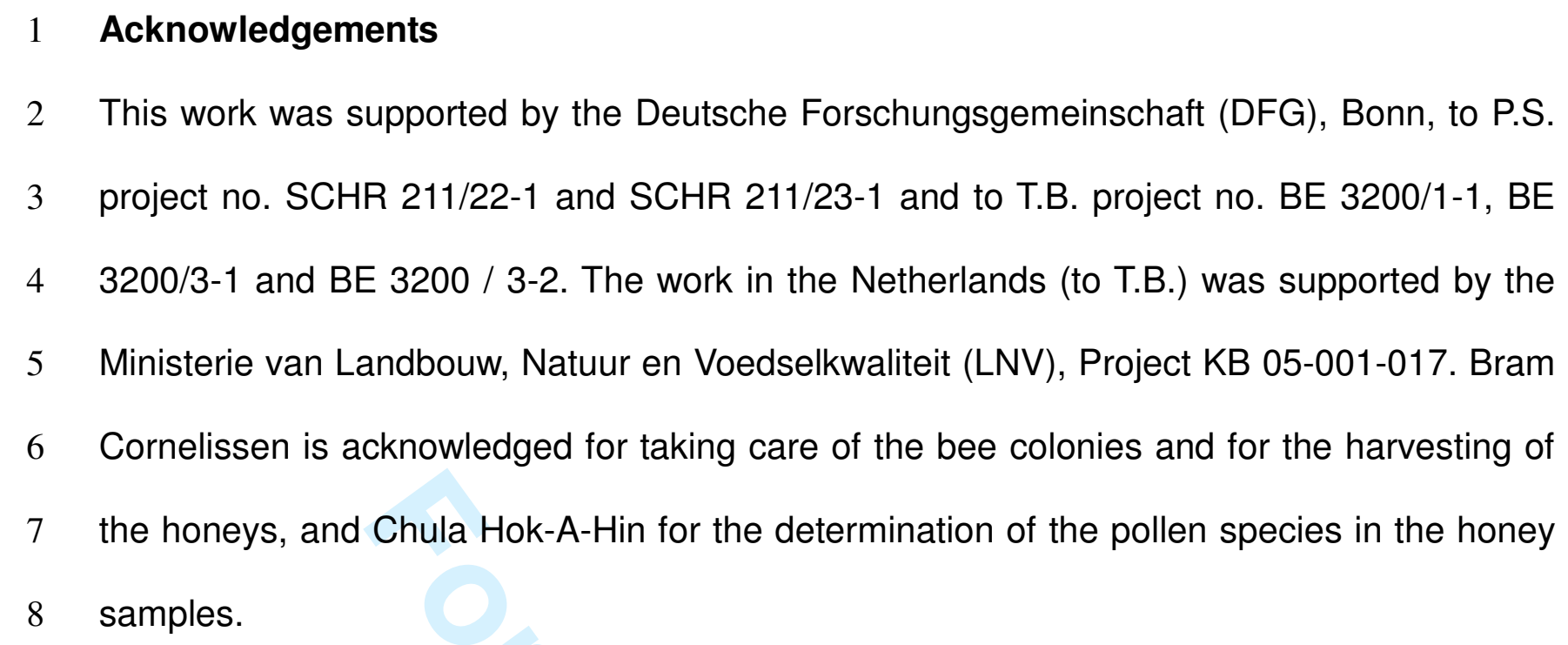

2 This work was supported by the Deutsche Forschungsgemeinschaft (DFG), Bonn, to P.S. 3 project no. SCHR 211/22-1 and SCHR 211/23-1 and to T.B. project no. BE 3200/1-1, BE 4 3200/3-1 and BE 3200 / 3-2. The work in the Netherlands (to T.B.) was supported by the 5 Ministerie van Landbouw, Natuur en Voedselkwaliteit (LNV), Project KB 05-001-017. Bram 6 Cornelissen is acknowledged for taking care of the bee colonies and for the harvesting of 7 the honeys, and Chula Hok-A-Hin for the determination of the pollen species in the honey 8 samples. 


\section{Literature}

Anastassiades M, Lehotay SJ, Štajnbaher D, Schenck FJ. 2003. Fast and easy multiresidue method employing acetonitrile extraction/partitioning and "dispersive solidphase extraction" for the determination of pesticide residues in products. J. AOAC Int. 86: 412-431.

Beales KA, Betteridge K, Colegate SM, Edgar JA. 2004. Solid-phase extraction and LCMS analysis of pyrrolizidine alkaloids in honeys. J Agr Food Chem. 52: 6664-6672.

Boppré M, Colegate SM, Edgar JA, Fischer OW. 2008. Hepatotoxic pyrrolizidine alkaloids in pollen and drying-related implications for commercial processing of bee pollen. J Agr Food Chem. 56: 5662-5672.

Crews C, Berthiller F, Krska R. 2010. Update on analytical methods for toxic pyrrolizidine alkaloids. Anal Bioanal Chem. 396: 327-338.

Colegate SM, Edgar JA, Knill AM, Lee ST. 2005. Solid-phase Extraction and HPLC-MS Profiling of Pyrrolizidine Alkaloids and their N-oxides: a Case Study of Echium plantagineum. Phytochem. 16: 108-119.

Cymerman Craig J, Purushothaman KK. 1970. An improved preparation of tertiary amine N-oxids. J Org Chem. 35: 1721-1722.

Edgar JA, Roeder E, Molyneux RJ. 2002. Honey from plants containing pyrrolizidine alkaloids: a potential threat to health. J Agr Food Chem. 50: 2719-2730.

El-Shazly A, Sarg T, Ateya A, Aziz EA, Witte L, Wink M. 1996. Pyrrolizidine alkaloids of Cynoglossum officinale and Cynoglossum amabile (Family Borginaceae). Biochem Sys Ecol. 24: 415-421.

El-Shazly A, El-Domiaty M, Witte L, Wink M. 1998. Pyrrolizidine alkaloids in members of the Boraginaceae from Sinai (Egypt). Biochem Sys Ecol. 26: 619-636.

European Commission. 2002. 2002/657/EC: Commission decision of 12 August 2002 implementing council directive 96/23/EC concerning the performance of analytical methods and the interpretation of results. Off J Eur Comm. L221: 8-36.

DIN. 2002. DIN 10760: Analysis of honey - Determination of the relative frequency of pollen. Deutsches Institut für Normung E.V. (German National Standard) / 01-May-2002

Froelich C, Ober D, Hartmann T. 2007. Tissue distribution, core biosynthesis and diversification of pyrrolizidine alkaloids of the lycopsamine type in three Boraginaceae species. Phytochem. 68: 1026-1037.

Hartmann T, Toppel G. 1987. Senecionine N-Oxide, the primary product of pyrrolizidine alkaloid biosynthesis in root culture of Senecio vulgaris. Phytochem. 26: 1639-1643.

Hartmann T, Ehmke A, Eilert U, Von Borstel K, Theuring C. 1989. Sites of synthesis, translocation and accumulation of pyrrolizidine alkaloid $\mathrm{N}$-Oxides in Senecio vulgaris. Planta. 177: 98-107. 
Hartmann T, Witte L. 1995. Alkaloids: Chemical and Biological Perspectives, vol. 9. Oxford: Pergamon Press. Chemistry, biology and chemoecology of the pyrrolizidine alkaloids, $p$. 155-233.

Hartmann T, Dierich B. 1998. Chemical diversity and variation of pyrrolizidine alkaloids of the senecionine type: biological need or coincidence? Planta. 206: 443-451.

Kempf M, Beuerle T, Bühringer M, Denner M, Trost D, Von der Ohe K, Bhavanam VBR, Schreier P. 2008. Pyrrolizidine alkaloids in honey: Risk analysis by gas chromatographymass spectrometry. Mol Nutr Food Res. 52: 1193-1200.

Kempf M, Reinhard A, Beuerle T. 2010a. Pyrrolizidine alkaloids (PAs) in honey and pollenlegal regulation of PA levels in food and animal feed required. Mol Nutr Food Res. 54: 158-168.

Kempf M, Heil S, Haßlauer I, Schmidt L, Von der Ohe K, Reinhard A, Schreier P, Beuerle T. 2010b. Pyrrolizidine alkaloids in pollen and pollen products. Mol Nutr Food Res. 54: 292-300.

Langer T, Franz C. 1997. Determination of pyrrolizidine alkaloids in commercial samples of borage seed oil products by GC-MS. Sci Pharm. 65: 321-328.

Liu F, Wan SY, Jiang Z, Li SFY, Ong ES, Castano O, Jhon C. 2009. Determination of pyrrolizidine alkaloids in comfrey by liquid chromatography-electrospray ionization mass spectrometry. Talanta. 80: 916-923.

Mattocks AR. 1986. Chemistry and toxicology of Pyrrolizidine Alkaloids. London: Academic Press.

Macel M, Vrieling K, Klinkhamer PGL. 2004. Variation in pyrrolizidine alkaloid patterns of Senecio jacobaea. Phytochem. 65: 865-873

Rizk A F M. 1991. Naturally occurring pyrrolizidine alkaloids. Boca Raton: CRC Press.

Roeder E. 1995. Medicinal plants in Europe containing pyrrolizidine alkaloids. Pharmazie. 50: 83-98.

Reinhard A, Jahnke M, Von der Ohe W, Kempf M, Theuring C, Hartmann T, Schreier P, Beuerle T. 2009. Feeding deterrence and detrimental effects mediated by toxic and nontoxic pyrrolizidine alkaloids fed to honey bees. J Chem Ecol. 35: 1086-1095.

Roeder E. 2000. Medicinal plants in China containing pyrrolizidine alkaloids. Pharmazie. 55: 711-726.

Somerville D. 2005. Fat Bees Skinny Bees - a manual on honey bee nutrition for beekeepers (Publication No. 05/054 Project No. DAN-186A). Barton (Australia):Rural Industries Research and Development Corporation (RIRDC).

Stegelmeier BL, Edgar JA, Steven M, Gardner DR, Schoch TK, Coulumbe RA, Molyneux RJ. 1999. Pyrrolizidine alkaloid plants, metabolism and toxicity. Journal of Natural Toxins. 8: 95-116. 
Toppel G, Witte L, Riebesehl B, Von Borstel K, Hartmann T. 1987. Alkaloid patterns and biosynthetic capacity of root cultures from some pyrrolizidine alkaloid producing Senecio species. Plant Cell Rep. 6: 466-469.

Von der Ohe W, Persano Oddo L, Piana ML, Morlot M, Martin P. 2004. Harmonized methods of melissopalynology. Apidologie 35(Suppl.1): 18-25.

VWA, Voedsel en waren autoriteit. Pyrrolizidine alkaloïden in honing [Internet]. 2007. Den Haag: Voedsel en waren autoriteit; [cited 2010 April 30]. Available from: http://www.vwa.nl/txmpub/files/?p_file_id=22703.

Wiedenfeld H, Pietrosiuk A, Furemanowa M, Roeder E. 2003. Pyrrolizidine alkaloids from Lithospermum canescens Lehm. J Biosc. 58: 173-176.

Witte L, Ernst L, Adam H, Hartmann T. 1992. Chemotypes of two pyrrolizidine alkaloidcontaining Senecio spp. Phytochem. 31: 559-566. 
Table 1: Major PA-containing bee forage plants identified by routine pollen analysis of raw honeys imported to Germany during the period 2007-2009 ( $n=$ several hundred; Intertek Food Services). The listed PA-structures and citations are exemplified. Where possible, honey related citations and structures were selected preferentially.

\begin{tabular}{|c|c|c|c|c|}
\hline plant family & genus / species & PA structures $^{1}$ & $\begin{array}{l}\text { nectar }^{2} / \text { pollen }^{3} \\
\text { abundance }\end{array}$ & $\begin{array}{c}\text { reference }^{4} / \text { geographic } \\
\text { distribution }^{5}\end{array}$ \\
\hline \multirow{4}{*}{ Boraginaceae } & Alkanna spp. & $\begin{array}{l}\text { triangularine, } \\
\text { dihydroxytriangularine, } \\
\text { 7-and 9-angeloylretronecine, }\end{array}$ & yes / unknown & $\begin{array}{l}\text { Roeder 1995; El-Shazly et } \\
\text { al. } 1998 \\
\text { unknown }\end{array}$ \\
\hline & Anchusa off. & $\begin{array}{l}\text { lycopsamine, intermedine }{ }^{6} \\
\text { and } 7- \\
\text { acetyllycopsamine/intermedine }\end{array}$ & yes / normal & $\begin{array}{l}\text { Hartmann and Witte 1995; } \\
\text { El-Shazly et al. } 1998 \\
\text { rare } \\
\text { Europe: common in dune } \\
\text { areas }\end{array}$ \\
\hline & Borago off. & $\begin{array}{l}\text { lycopsamine, intermedine }{ }^{6}, \\
7- \\
\text { acetyllycopsamine/intermedine, } \\
\text { amabiline and supinine }\end{array}$ & yes / low to normal & $\begin{array}{l}\text { Roeder 1995; Langer and } \\
\text { Franz } 1997 \\
\text { Northern Europe } \\
\text { (UK/Scottland), } \\
\text { New Zealand } \\
\text { France, Chile, Italy } \\
\text { Europe: used for oil seed } \\
\text { production }\end{array}$ \\
\hline & Cynoglossum off. & $\begin{array}{l}\text { echinatine }^{6} \text {, rinderine } \\
\text { heliosupine, } \\
\text { 7-angeloylheliotridine, } \\
\text { 7-angeloyl-9- (2-methylbutyryl) } \\
\text { and heliotridine }\end{array}$ & yes / normal to high & $\begin{array}{l}\text { El-Shazly et al. 1996; } \\
\text { Froelich et al. } 2007 \\
\text { Central and East Europe } \\
\text { (Austria, Hungary, } \\
\text { Slovakia) }\end{array}$ \\
\hline
\end{tabular}




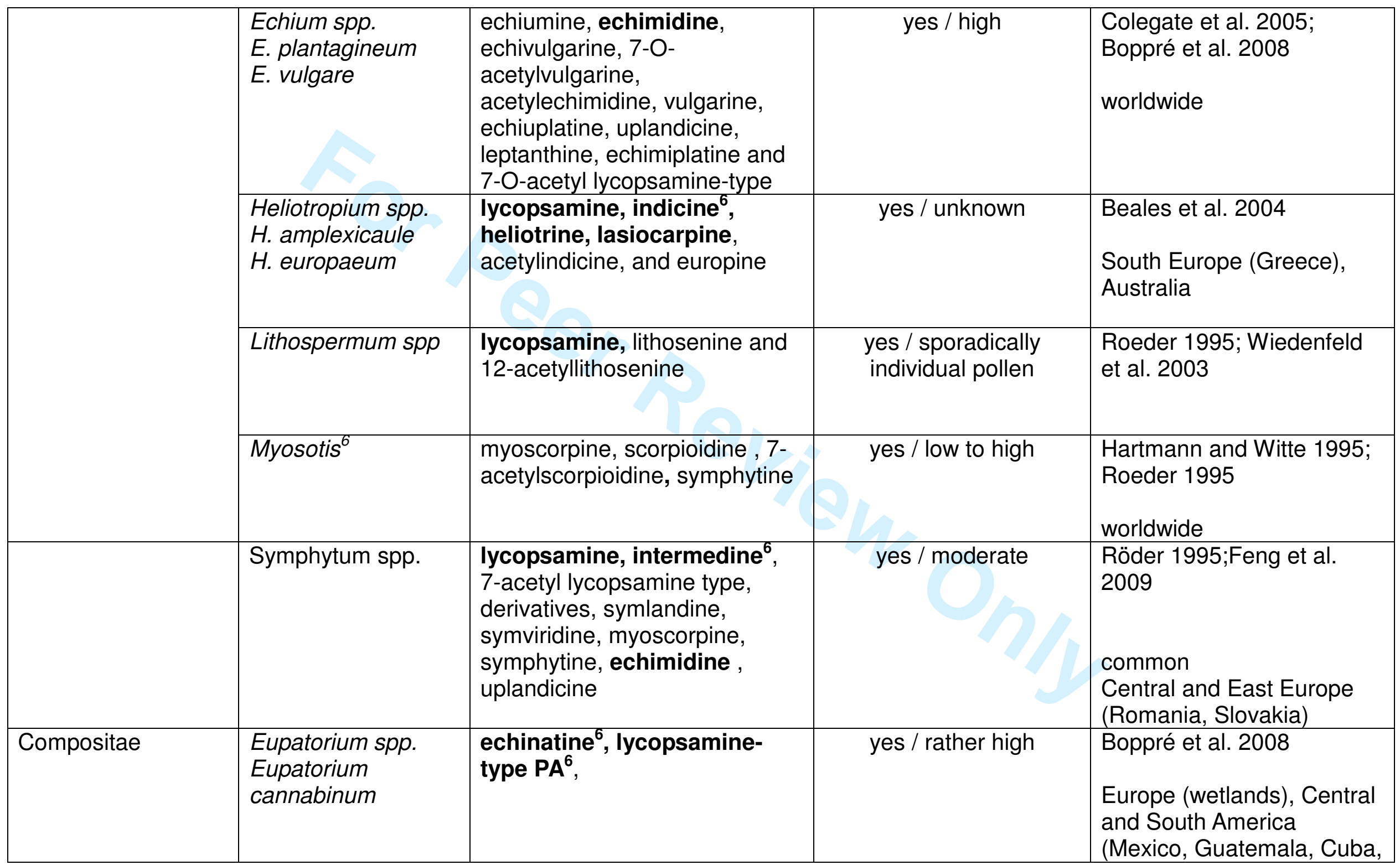




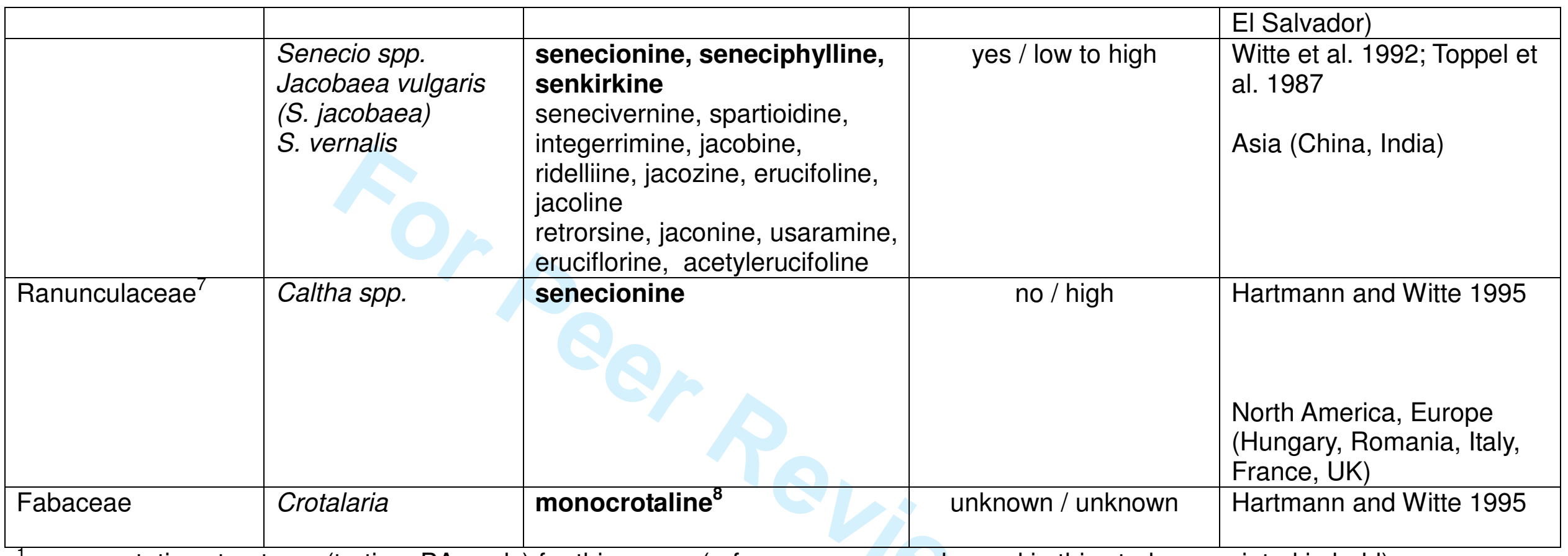

${ }^{1}$ representative structures (tertiary PAs only) for this genus (reference compounds used in this study are printed in bold)

${ }^{2}$ bee keeper information: plant is a known nectar source for honey bees

${ }^{3}$ bee keeper information: pollen abundance in honey for this forage plant

${ }_{5}^{4}$ selected references on PA-content for this genus

${ }^{5}$ based on results for routine pollen analysis of import honeys

${ }^{6}$ isomer of lycopsamine

${ }^{7}$ little or no data available

${ }^{8}$ so far never detected in honey 


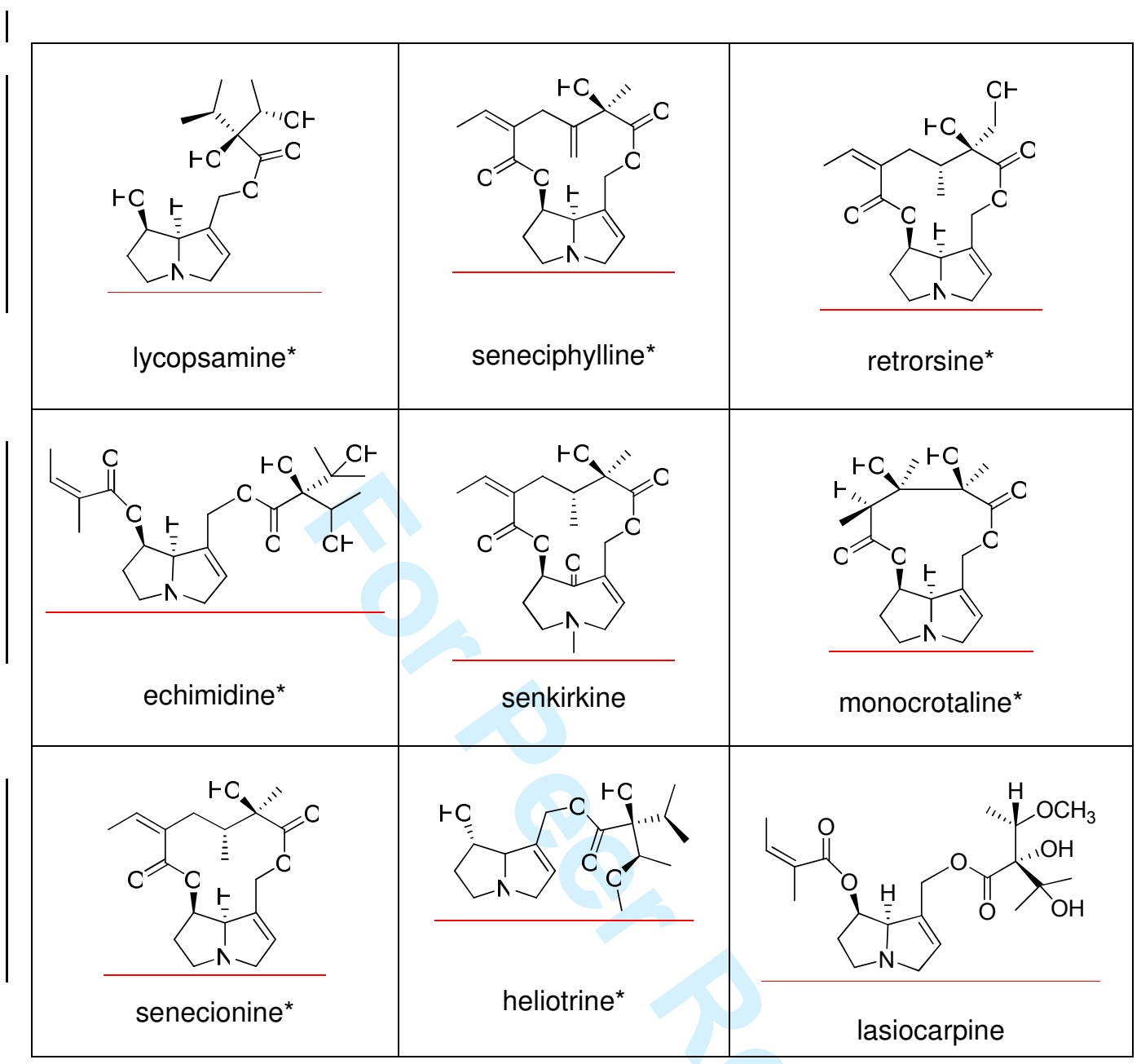

Figure 1: Structures of commercially available PAs used as reference compounds in this study. * The $\mathrm{N}$-oxides of echimidine, heliotrine, lycopsamine, monocrotaline, retrorsine, senecionine and seneciphylline were chemically synthesized. 


\section{GC-MS Method}

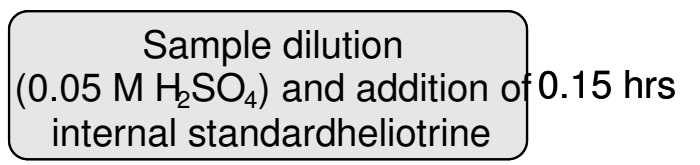

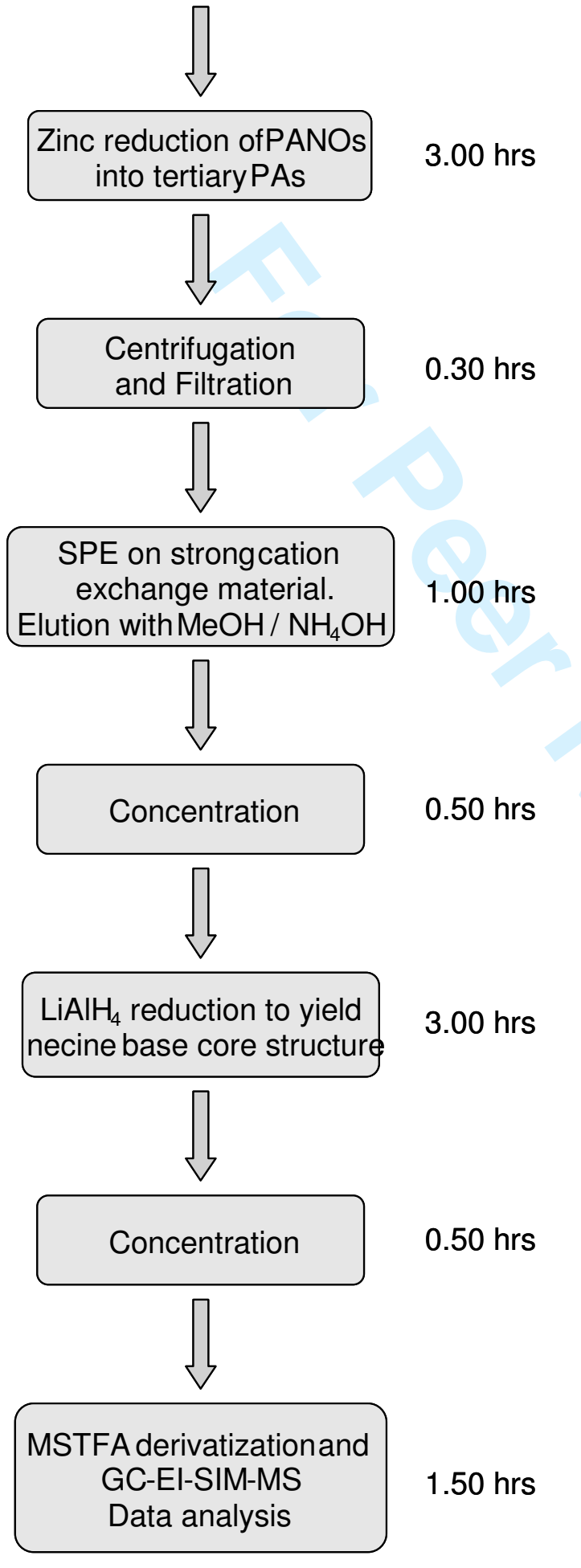

approximate time necessary: $10 \mathrm{hrs}$

\section{LC-ESI-MS-MS Method}

$0.15 \mathrm{hrs} \quad \begin{aligned} & \text { Sample Dilution }\left(\mathrm{H}_{2} \mathrm{O}\right) \text { and } \\ & \text { addition of internal standard }\end{aligned}$ Isoproturon-d6

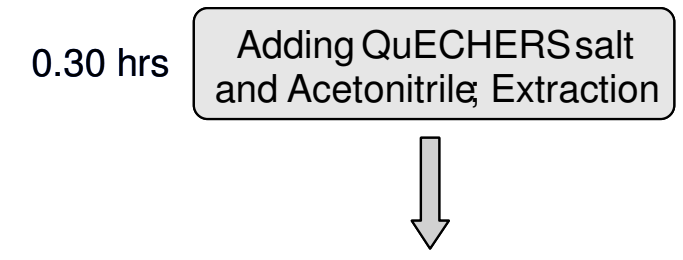

$0.10 \mathrm{hrs}$

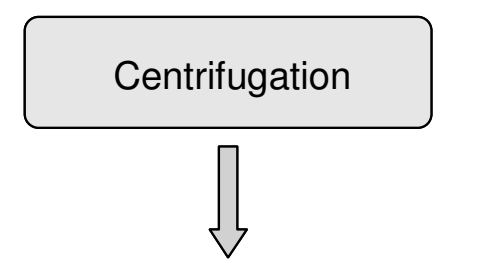

$0.20 \mathrm{hrs}$

Transferring Acetonitrile; Adding $\mathrm{MgSO}_{4}$.

$0.10 \mathrm{hrs}$

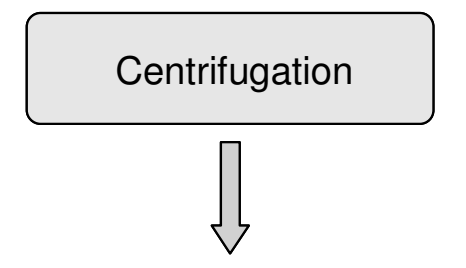

$1.00 \mathrm{hrs}$

\section{Transferring Acetonitril;} Concentration

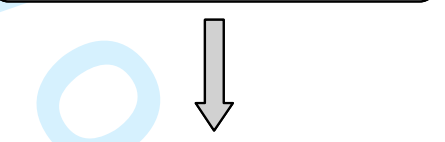

$0.10 \mathrm{hrs}$

Reconstitution; Homogenization

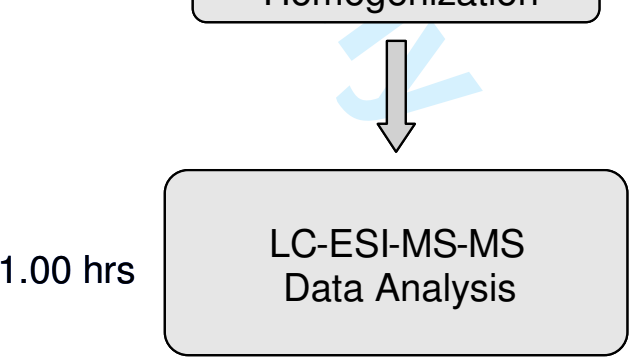

\section{$3 \mathrm{hrs}$ :approximate time necessary}

Figure 2: $\quad$ Schematic diagram of the key steps and the required time for sample preparation for both analytical methods. 


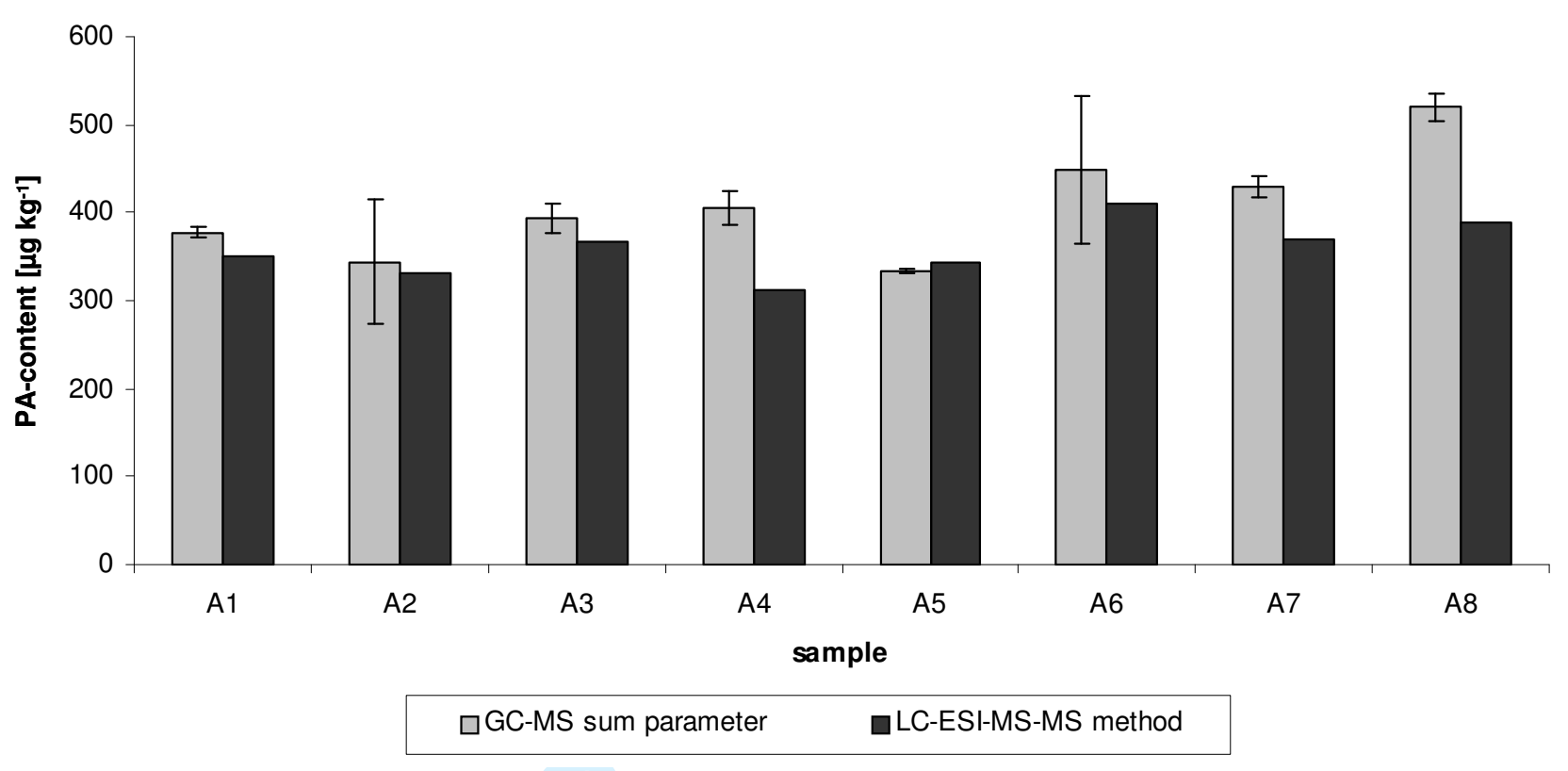

Figure 3: $\quad$ Comparison of the total PA-content of Echium honeys $(n=8$; set A; New Zealand) calculated in retronecine equivalents. Left (gray) bars GC-MS sum parameter approach (SD; $n=3$ ), right (black) bars LC-MSMS method, respectively. 
Figure 4: $\quad$ Comparison of the total PA-content of randomly picked raw honeys $(n=$ 8; set B) calculated in retronecine equivalents. Left (gray) bars GC-MS sum parameter approach $(S D ; n=3)$, right (black) bars LC-MS-MS method, respectively. 
Table 2: Direct comparison of the advantages and disadvantages of both methods that were observed during the implementation of both methods

\begin{tabular}{|c|c|}
\hline $\begin{array}{c}\text { GC-MS } \\
\text { sum parameter approach }\end{array}$ & $\begin{array}{c}\text { LC-ESI-MS-MS } \\
\text { target PA approach }\end{array}$ \\
\hline $\begin{array}{l}\text { Pros } \\
+ \text { low chance to miss toxic relevant PAs } \\
+ \text { true internal standard quantification } \\
+ \text { simple quantification } \\
+ \text { can be easily adapted to different samples } \\
\text { and background } \\
+ \text { no need of background information of the } \\
\text { samples or PAs involved } \\
+ \text { low dependency from standards } \\
+ \text { can be adapted to stable isotope dilution } \\
\text { analysis }\end{array}$ & $\begin{array}{l}\text { Pros } \\
+N \text {-Oxides and tertiary PA can be } \\
\text { determined simultaneously } \\
\text { + proportion of each individual structure } \\
\text { will be known which might be necessary } \\
\text { for further toxicological aspects } \\
\text { + low efforts for sample preparation } \\
\text { + fast turnaround times } \\
\text { + LOQ of 1 ppb } \\
\text { + more informative (PA-plant patterns, } \\
\text { ratio tertiary PAs/PANOs, link to } \\
\text { geographic origin) } \\
\text { + QuEChERS workup can be used }\end{array}$ \\
\hline $\begin{array}{l}\text { Cons } \\
\text { - toxic otonecine-PAs are not covered } \\
\text { - structural information of the original PAs } \\
\text { is lost and possible differences between } \\
\text { toxicological properties are not recorded } \\
\text { - N-Oxide reduction is necessary } \\
\text { - labor intensive sample work-up } \\
\text { - double workup (with and without internal } \\
\text { standard } \\
\text { - lengthy turn-around time } \\
\text { - LOQ of } 10 \mathrm{ppb}\end{array}$ & $\begin{array}{l}\text { Cons } \\
\text { - unknown or unexpected PAs are missed } \\
\text { - strong dependency on the availability of } \\
\text { standard compounds } \\
\text { - solid quantification needs many standard } \\
\text { compounds } \\
\text { - knowledge of the history of the samples is } \\
\text { helpful } \\
\text { - external quantification or quantification } \\
\text { through standard addition } \\
\text { - additional expenditure for data evaluation }\end{array}$ \\
\hline
\end{tabular}




\begin{tabular}{cccccc}
\hline \multirow{2}{*}{ Sample } & \multirow{2}{*}{ Origin } & \multicolumn{3}{c}{ PA-content $\left[\mathrm{\mu g} \mathrm{kg}^{-1}\right]$} & \\
\cline { 3 - 5 } & mean & SD sum paramter & LC-ESI-MS-MS & \multirow{2}{*}{ Pollen analysis } \\
\hline A1 & New Zealand & 378 & 6 & 351 & $61 \%$ Echium spp. \\
A2 & New Zealand & 344 & 71 & 332 & $62 \%$ Echium spp. \\
A3 & New Zealand & 394 & 17 & 367 & $62 \%$ Echium spp. \\
A4 & New Zealand & 406 & 20 & 311 & $68 \%$ Echium spp. \\
A5 & New Zealand & 334 & 3 & 344 & $66 \%$ Echium spp. \\
A6 & New Zealand & 449 & 84 & 411 & $61 \%$ Echium spp. \\
A7 & New Zealand & 429 & 12 & 370 & $72 \%$ Echium spp. \\
A8 & New Zealand & 520 & 15 & 389 & $80 \%$ Echium spp. \\
\hline
\end{tabular}




\begin{tabular}{cccccc}
\hline & & \multicolumn{3}{c}{ PA-content $\left[\mathrm{\mu g} \mathrm{kg}^{-1}\right]$} & \\
\cline { 3 - 5 } Sample & Origin & GC-MS sum paramter & LC-ESI-MS-MS & Pollen analysis \\
\cline { 3 - 5 } B1 & Cuba & traces & SD $(\mathrm{n}=3)$ & 0 & $9 \%$ Eupatorium spp. \\
B2 & Australia & 590 & n.C. & 65 & $7 \%$ Echium spp. \\
B3 & Cuba & 65 & 1 & 42 & sporadic Eupatorium spp. \\
B4 & England & traces & n.c. & 1 & sporadic Borago spp. \\
B5 & Spain & traces & n.c. & 1 & $10 \%$ Echium spp. \\
B6 & Cuba & 135 & 10 & 119 & $7 \%$ Eupatorium spp. \\
B7 & Guatemala & 23 & 2 & 18 & $15 \%$ Eupatorium spp. \\
B8 & Argentina & n.d. & n.d. & 0 & sporadic Echium spp. \\
\hline n.d. $=$ not detecable & & & &
\end{tabular}

n.c. $=$ not able to calculate 


\begin{tabular}{|c|c|c|c|c|c|}
\hline \multirow[b]{3}{*}{ Sample } & \multirow[b]{3}{*}{ Origin } & \multirow{2}{*}{\multicolumn{3}{|c|}{ PA-content $\left[\mu \mathrm{g} \mathrm{kg}^{-1}\right]$}} & \multirow[b]{3}{*}{ Pollen analysis } \\
\hline & & & & & \\
\hline & & \multicolumn{2}{|c|}{ GC-MS sum paramter } & LC-ESI-MS-MS & \\
\hline $\mathrm{C} 1-1$ & the Netherlands, PW2007 & 13019 & 85 & 544 & 1,8\% Senecio spp. \\
\hline C1-2 & the Netherlands, PW2007 & 4797 & 87 & 120 & $3,8 \%$ Senecio spp. \\
\hline C1-3 & the Netherlands, SH2007 & 1756 & 139 & 55 & 1,6\% Senecio spp. \\
\hline C1-4 & the Netherlands, SH2007 & 2148 & 10 & 49 & $2,2 \%$ Senecio spp. \\
\hline $\mathrm{C} 2-1$ & the Netherlands, SH2008 & 124 & 45 & 15 & 1,6\% Senecio spp. \\
\hline $\mathrm{C} 2-2$ & the Netherlands, SH2008 & 537 & 180 & 63 & n.d. \\
\hline $\mathrm{C} 2-3$ & the Netherlands, SH2008 & 38 & 5 & 31 & 1,3\% Senecio spp. \\
\hline $\mathrm{C} 2-4$ & the Netherlands, SH2008 & n.d. & n.d. & 3 & n.p. \\
\hline $\mathrm{C} 2-5$ & the Netherlands, RK2008 & 250 & 10 & 10 & 0,6\% Senecio spp. \\
\hline $\mathrm{C} 2-6$ & the Netherlands, RK2008 & 232 & 15 & 56 & 0,6\% Senecio spp. \\
\hline $\mathrm{C} 2-7$ & the Netherlands, RK2008 & 3796 & 110 & 85 & 1,0\% Senecio spp. \\
\hline $\mathrm{C} 2-8$ & the Netherlands, RK2008 & 1751 & 106 & 29 & 1,8\% Senecio spp. \\
\hline $\mathrm{C} 2-9$ & the Netherlands, GR2008 & 226 & 6 & 52 & n.p. \\
\hline $\mathrm{C} 2-10$ & the Netherlands, GR2008 & 304 & 6 & 73 & n.p. \\
\hline $\mathrm{C} 2-11$ & the Netherlands, GR2008 & 525 & 165 & 22 & n.p. \\
\hline $\mathrm{C} 2-12$ & the Netherlands, GR2008 & 4658 & 800 & 813 & 1,4\% Senecio spp. \\
\hline $\mathrm{C} 2-13$ & the Netherlands, PW2008 & n.d. & n.d. & 0 & n.p. \\
\hline C2-14 & the Netherlands, SH2008 & 52 & 25 & 11 & 1,0\% Senecio spp. \\
\hline $\mathrm{C} 2-15$ & the Netherlands, SH2008 & 20 & 5 & 8 & n.p. \\
\hline $\mathrm{C} 2-16$ & the Netherlands, SH2008 & 22 & 5 & 11 & n.p. \\
\hline $\mathrm{C} 2-17$ & the Netherlands, SH2008 & 107 & 41 & 21 & 6,3\% Senecio spp. \\
\hline C2-18 & the Netherlands, RK2008 & 300 & 10 & 51 & n.p. \\
\hline C2-19 & the Netherlands, RK2008 & 248 & 29 & 20 & n.p. \\
\hline C2-20 & the Netherlands, RK2008 & 268 & 24 & 19 & n.p. \\
\hline $\mathrm{C} 2-21$ & the Netherlands, RK2008 & 354 & 28 & 42 & n.p. \\
\hline C2-22 & the Netherlands, RK2008 & 712 & 118 & 73 & n.p. \\
\hline C2-23 & the Netherlands, GR2008 & 217 & 104 & 51 & n.p. \\
\hline C2-24 & the Netherlands, GR2008 & 2604 & 133 & 21 & 0,6\% Senecio spp. \\
\hline C2-25 & the Netherlands, PW2008 & n.d. & n.d. & 0 & n.p. \\
\hline C2-26 & the Netherlands, PW2008 & 38 & 7 & 16 & n.p. \\
\hline $\mathrm{C} 2-27$ & the Netherlands, GR2008 & n.d. & n.d. & 2 & n.p. \\
\hline
\end{tabular}

n.d. = no PA-plant Pollen detecable

n.p. $=$ not performed 
Single PA-content

\begin{tabular}{|c|c|c|c|c|c|c|c|c|c|c|c|c|c|c|c|c|c|}
\hline sample & $\begin{array}{c}\text { echimidine } \\
{\left[\mu \mathrm{gkg}^{-1}\right]}\end{array}$ & $\begin{array}{l}\text { echimidine- } N \text {-oxide } \\
{\left[\mu \mathrm{g} \mathrm{kg}{ }^{-1}\right]}\end{array}$ & $\begin{array}{l}\text { heliotrine } \\
{\left[\mu \mathrm{kg}^{-1}\right]}\end{array}$ & $\begin{array}{c}\text { heliotrine- } N \text {-oxide } \\
{\left[\mu \mathrm{gg} \mathrm{g}^{-1}\right]}\end{array}$ & $\begin{array}{c}\text { lycopsamine } \\
{\left[\mathrm{\mu g} \mathrm{kg}^{-1}\right]}\end{array}$ & $\begin{array}{c}\text { lycopsamin- } N \text {-oxide } \\
{\left[\mu \mathrm{kg}^{-1}\right]}\end{array}$ & $\begin{array}{c}\text { senecionine } \\
{\left[\mu \mathrm{g} \mathrm{kg}^{-1}\right]}\end{array}$ & $\begin{array}{c}\text { senecionin- } N \text {-oxide } \\
{\left[\mu \mathrm{kg}^{-1}\right]}\end{array}$ & $\begin{array}{l}\text { seneciphylline } \\
{\left[\mu g \mathrm{~kg}^{-1}\right]}\end{array}$ & $\begin{array}{c}\text { seneciphyllin- } N \text {-oxide } \\
{\left[\mu \mathrm{kg}^{-1}\right]}\end{array}$ & $\begin{array}{c}\text { senkirkine } \\
{\left[\mu \mathrm{ggg}^{-1}\right]}\end{array}$ & $\begin{array}{c}\text { monocrotaline } \\
{\left[\mu \mathrm{g} \mathrm{kg}^{-1}\right]}\end{array}$ & $\begin{array}{c}\text { monocrotaline- } N \text {-oxide } \\
{\left[\mu \mathrm{kg}^{-1}\right]}\end{array}$ & $\begin{array}{c}\text { lasiocarpine } \\
{\left[\mathrm{\mu g} \mathrm{kg}^{-1}\right]}\end{array}$ & $\begin{array}{l}\text { retrorsine } \\
{\left[\mu \mathrm{kg}^{-1}\right]}\end{array}$ & $\begin{array}{c}\text { retrorsine- } N \text {-oxide } \\
{\left[\mu \mathrm{kg}^{-1}\right]}\end{array}$ & $\begin{array}{l}\text { total PA } \\
{\left[\mu \mathrm{kg} g^{-1}\right]}\end{array}$ \\
\hline$\overline{\mathrm{A} 1}$ & 885 & 11 & $\overline{0}$ & 0 & 2 & $\overline{0}$ & 0 & $\overline{0}$ & $\overline{0}$ & $\overline{0}$ & $\overline{0}$ & $\overline{0}$ & $\overline{0}$ & $\overline{0}$ & $\overline{0}$ & $\overline{0}$ & 898 \\
\hline A2 & 837 & 10 & 0 & 0 & 2 & 0 & 0 & 0 & 0 & 0 & 0 & 0 & 0 & 0 & 0 & 0 & 849 \\
\hline A3 & 929 & 9 & 0 & 0 & 1 & 0 & 0 & 0 & 0 & 0 & 0 & 0 & 0 & 0 & 0 & 0 & 939 \\
\hline A4 & 793 & 2 & 0 & 0 & 1 & 0 & 0 & 0 & 0 & 0 & 0 & 0 & 0 & 0 & 0 & 0 & 796 \\
\hline A5 & 875 & 5 & 0 & 0 & 0 & 0 & 0 & 0 & 0 & 0 & 0 & 0 & 0 & 0 & 0 & 0 & 880 \\
\hline A6 & 1046 & 3 & 0 & 0 & 2 & 0 & 0 & 0 & 0 & 0 & 0 & 0 & 0 & 0 & 0 & 0 & 1051 \\
\hline A7 & 944 & 3 & 0 & 0 & 1 & 0 & 0 & 0 & 0 & 0 & 0 & 0 & 0 & 0 & 0 & 0 & 948 \\
\hline A8 & 989 & 5 & 0 & 0 & 1 & 0 & 0 & 0 & 0 & 0 & 0 & 0 & 0 & 0 & 0 & 0 & 995 \\
\hline B1 & 0 & 0 & 0 & 0 & 0 & 0 & 0 & 0 & 0 & 0 & 0 & 0 & 0 & 0 & 0 & 0 & 0 \\
\hline B2 & 39 & 0 & 5 & 0 & 1171 & 0 & 0 & 0 & 0 & 0 & 0 & 0 & 0 & 0 & 0 & 0 & 1215 \\
\hline B3 & 0 & 0 & 0 & 0 & 80 & 0 & 0 & 1 & 0 & 0 & 0 & 0 & 0 & 0 & 0 & 0 & 81 \\
\hline B4 & 0 & 0 & 0 & 0 & 2 & 0 & 0 & 0 & 0 & 0 & 0 & 0 & 0 & 0 & 0 & 0 & 2 \\
\hline B5 & 2 & 0 & 0 & 0 & 1 & 0 & 0 & 0 & 0 & 0 & 0 & 0 & 0 & 0 & 0 & 0 & 3 \\
\hline B6 & 0 & 0 & 0 & 0 & 224 & 5 & 0 & 0 & 0 & 0 & 0 & 0 & 0 & 0 & 0 & 0 & 229 \\
\hline B7 & 0 & 0 & 0 & 0 & 34 & 0 & 0 & 0 & 0 & 0 & 0 & 0 & 0 & 0 & 0 & 0 & 34 \\
\hline B8 & 0 & 0 & 0 & 0 & 0 & 0 & 0 & 0 & 0 & 0 & 0 & 0 & 0 & 0 & 0 & 0 & 0 \\
\hline C1-1 & 0 & 0 & 0 & 0 & 0 & 0 & 513 & 80 & 579 & 4 & 0 & 0 & 0 & 0 & 0 & 0 & 1176 \\
\hline $\mathrm{C} 1-2$ & 0 & 0 & 0 & 0 & 0 & 0 & 115 & 22 & 95 & 30 & 0 & 0 & 0 & 0 & 0 & 0 & 262 \\
\hline $\mathrm{C} 1-3$ & 0 & 0 & 0 & 0 & 0 & 0 & 29 & 26 & 31 & 36 & 0 & 0 & 0 & 0 & 0 & 0 & 122 \\
\hline C1-4 & 0 & 0 & 0 & 0 & 0 & 0 & 29 & 18 & 29 & 32 & 0 & 0 & 0 & 0 & 0 & 0 & 108 \\
\hline $\mathrm{C} 2-1$ & 0 & 0 & 0 & 0 & 0 & 0 & 9 & 8 & 10 & 7 & 0 & 0 & 0 & 0 & 0 & 0 & 34 \\
\hline C2-2 & 0 & 0 & 0 & 0 & 0 & 0 & 13 & 49 & 17 & 62 & 0 & 0 & 0 & 0 & 0 & 0 & 141 \\
\hline C2-3 & 0 & 0 & 0 & 0 & 0 & 0 & 12 & 28 & 6 & 23 & 0 & 0 & 0 & 0 & 0 & 0 & 69 \\
\hline C2-4 & 0 & 0 & 0 & 0 & 0 & 0 & 3 & 0 & 3 & 0 & 0 & 0 & 0 & 0 & 0 & 0 & 6 \\
\hline C2-5 & 0 & 0 & 0 & 0 & 0 & 0 & 2 & 9 & 2 & 10 & 0 & 0 & 0 & 0 & 0 & 0 & 23 \\
\hline $\mathrm{C} 2-6$ & 0 & 0 & 0 & 0 & 0 & 0 & 27 & 39 & 26 & 32 & 0 & 0 & 0 & 0 & 0 & 0 & 124 \\
\hline C2-7 & 0 & 0 & 0 & 0 & 0 & 14 & 30 & 57 & 32 & 54 & 0 & 0 & 0 & 0 & 0 & 0 & 187 \\
\hline $\mathrm{C} 2-8$ & 0 & 0 & 0 & 0 & 0 & 0 & 3 & 24 & 4 & 34 & 0 & 0 & 0 & 0 & 0 & 0 & 65 \\
\hline C2-9 & 0 & 0 & 0 & 0 & 0 & 0 & 59 & 5 & 45 & 3 & 0 & 0 & 0 & 0 & 0 & 0 & 112 \\
\hline C2-10 & 0 & 0 & & 0 & 0 & 0 & 30 & 57 & 23 & 52 & 0 & 0 & 0 & 0 & 0 & 0 & 162 \\
\hline C2-11 & 0 & 0 & 0 & 0 & 0 & 0 & 7 & 16 & 8 & 19 & 0 & 0 & 0 & 0 & 0 & 0 & 50 \\
\hline C2-12 & 0 & 0 & 0 & 0 & 0 & 0 & 419 & 364 & 440 & 570 & 0 & 0 & 0 & 0 & 0 & 0 & 1793 \\
\hline C2-13 & 0 & 0 & 0 & 0 & 0 & 0 & 0 & 0 & 0 & 0 & 0 & 0 & 0 & 0 & 0 & 0 & 0 \\
\hline C2-14 & 0 & 0 & 0 & 0 & 0 & 0 & 7 & 9 & 5 & 3 & 0 & 0 & 0 & 0 & 0 & 0 & 23 \\
\hline C2-15 & 0 & 0 & 0 & 0 & 0 & 0 & 6 & 6 & 4 & 1 & 0 & 0 & 0 & 0 & 0 & 0 & 17 \\
\hline C2-16 & 0 & 0 & 0 & 0 & 0 & 0 & 6 & 12 & 3 & 4 & 0 & 0 & 0 & 0 & 0 & 0 & 25 \\
\hline C2-17 & 0 & 0 & 0 & 0 & 0 & 0 & 11 & 17 & 8 & 10 & 0 & 0 & 0 & 0 & 0 & 0 & 46 \\
\hline C2-18 & 0 & 0 & 0 & 0 & 0 & 0 & 21 & 33 & 17 & 42 & 0 & 0 & 0 & 0 & 0 & 0 & 113 \\
\hline C2-19 & 0 & 0 & 0 & 0 & 0 & 0 & 21 & 8 & 12 & 3 & 0 & 0 & 0 & 0 & 0 & 0 & 44 \\
\hline C2-20 & 0 & 0 & 0 & 0 & 0 & 0 & 22 & 6 & 12 & 1 & 0 & 0 & 0 & 0 & 0 & 0 & 41 \\
\hline C2-21 & 0 & 0 & 0 & 0 & 0 & 0 & 11 & 28 & 14 & 41 & 0 & 0 & 0 & 0 & 0 & 0 & 94 \\
\hline C2-22 & 0 & 0 & 0 & 0 & 0 & 0 & 28 & 51 & 25 & 58 & 0 & 0 & 0 & 0 & 0 & 0 & 162 \\
\hline C2-23 & 0 & 0 & 0 & 0 & 0 & 0 & 34 & 35 & 29 & 14 & 0 & 0 & 0 & 0 & 0 & 0 & 112 \\
\hline C2-24 & 0 & 0 & 0 & 0 & 0 & 0 & 18 & 9 & 16 & 3 & 0 & 0 & 0 & 0 & 0 & 0 & 46 \\
\hline C2-25 & 0 & 0 & 0 & 0 & 0 & 0 & 0 & 0 & 0 & 0 & 0 & 0 & 0 & 0 & 0 & 0 & 0 \\
\hline C2-26 & 0 & 0 & 0 & 0 & 0 & 0 & 2 & 8 & 4 & 21 & 0 & 0 & 0 & 0 & 0 & 0 & 35 \\
\hline C2-27 & 0 & 0 & 0 & 0 & 0 & 0 & 2 & 0 & 2 & 0 & 0 & 0 & 0 & 0 & 0 & 0 & 4 \\
\hline
\end{tabular}


Single PAs calculated as retronecine equivalents

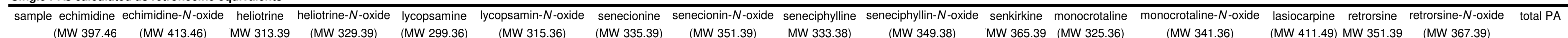
(MW $397.46 \quad$ (MW 413.46) MW 313.39

MW 333.38) (MW 349.38)

(MW 341.36)

(MW 411.49) MW $351.39 \quad$ (MW 367.39)

\begin{tabular}{|c|c|c|c|c|c|c|c|c|c|c|c|c|c|c|c|c|c|}
\hline & {$\left[\mathrm{\mu g} \mathrm{kg}^{-1}\right]$} & {$\left[\mu \mathrm{g} \mathrm{kg}^{-1}\right]$} & {$\left[\mu \mathrm{kg} \mathrm{k}^{-1}\right]$} & {$\left[\mu \mathrm{g} \mathrm{kg}^{-1}\right]$} & {$\left[\mu \mathrm{g} \mathrm{kg}^{-1}\right]$} & {$\left[\mathrm{\mu g} \mathrm{kg}^{-1}\right]$} & {$\left[\mathrm{g} \mathrm{kg} \mathrm{k}^{-1}\right]$} & {$\left[\mu \mathrm{kg}^{-1}\right]$} & {$\left[\mu \mathrm{g} \mathrm{kg}^{-1}\right]$} & {$\left[\mathrm{\mu g} \mathrm{kg}^{-1}\right]$} & {$\left[\mathrm{\mu g} \mathrm{kg}^{-1}\right]$} & {$\left[\mu \mathrm{g} \mathrm{kg}^{-1}\right]$} & {$\left[\mu \mathrm{g} \mathrm{kg}^{-1}\right]$} & {$\left[\mu \mathrm{kg} \mathrm{k}^{-1}\right]$} & {$\left[\mu \mathrm{g} \mathrm{kg}^{-1}\right]$} & {$\left[\mathrm{ug} \mathrm{kg}^{-1}\right]$} & {$\left[\mu \mathrm{g} \mathrm{kg}^{-1}\right]$} \\
\hline$\overline{\mathrm{A} 1}$ & 346 & 4 & 0 & 0 & 1 & 0 & 0 & 0 & 0 & 0 & 0 & 0 & 0 & 0 & 0 & 0 & 351 \\
\hline A2 & 327 & 4 & 0 & 0 & 1 & 0 & 0 & 0 & 0 & 0 & 0 & 0 & 0 & 0 & 0 & 0 & 332 \\
\hline A3 & 363 & 3 & 0 & 0 & 1 & 0 & 0 & 0 & 0 & 0 & 0 & 0 & 0 & 0 & 0 & 0 & 367 \\
\hline A4 & 310 & 1 & 0 & 0 & 1 & 0 & 0 & 0 & 0 & 0 & 0 & 0 & 0 & 0 & 0 & 0 & 311 \\
\hline A5 & 342 & 2 & 0 & 0 & 0 & 0 & 0 & 0 & 0 & 0 & 0 & 0 & 0 & 0 & 0 & 0 & 344 \\
\hline A6 & 408 & 1 & 0 & 0 & 1 & 0 & 0 & 0 & 0 & 0 & 0 & 0 & 0 & 0 & 0 & 0 & 411 \\
\hline A7 & 369 & 1 & 0 & 0 & 1 & 0 & 0 & 0 & 0 & 0 & 0 & 0 & 0 & 0 & 0 & 0 & 370 \\
\hline A8 & 386 & 2 & 0 & 0 & 1 & 0 & 0 & 0 & 0 & 0 & 0 & 0 & 0 & 0 & 0 & 0 & 389 \\
\hline $\mathrm{B} 1$ & 0 & 0 & 0 & 0 & 0 & 0 & 0 & 0 & 0 & 0 & 0 & 0 & 0 & 0 & 0 & 0 & 0 \\
\hline B2 & 15 & 0 & 2 & 0 & 607 & 0 & 0 & 0 & 0 & 0 & 0 & 0 & 0 & 0 & 0 & 0 & 625 \\
\hline B3 & 0 & 0 & 0 & 0 & 42 & 0 & 0 & 0 & 0 & 0 & 0 & 0 & 0 & 0 & 0 & 0 & 42 \\
\hline B4 & 0 & 0 & 0 & 0 & 1 & 0 & 0 & 0 & 0 & 0 & 0 & 0 & 0 & 0 & 0 & 0 & 1 \\
\hline B5 & 1 & 0 & 0 & 0 & 1 & 0 & 0 & 0 & 0 & 0 & 0 & 0 & 0 & 0 & 0 & 0 & 1 \\
\hline B6 & 0 & 0 & 0 & 0 & 116 & 2 & 0 & 0 & 0 & 0 & 0 & 0 & 0 & 0 & 0 & 0 & 119 \\
\hline B7 & 0 & 0 & 0 & 0 & 18 & 0 & 0 & 0 & 0 & 0 & 0 & 0 & 0 & 0 & 0 & 0 & 18 \\
\hline B8 & 0 & 0 & 0 & 0 & 0 & 0 & 0 & 0 & 0 & 0 & 0 & 0 & 0 & 0 & 0 & 0 & 0 \\
\hline C1-1 & 0 & 0 & 0 & 0 & 0 & 0 & 237 & 35 & 270 & 2 & 0 & 0 & 0 & 0 & 0 & 0 & 544 \\
\hline C1-2 & 0 & 0 & 0 & 0 & 0 & 0 & 53 & 10 & 44 & 13 & 0 & 0 & 0 & 0 & 0 & 0 & 120 \\
\hline C1-3 & 0 & 0 & 0 & 0 & 0 & 0 & 13 & 11 & 14 & 16 & 0 & 0 & 0 & 0 & 0 & 0 & 55 \\
\hline C1-4 & 0 & 0 & 0 & 0 & 0 & 0 & 13 & 8 & 13 & 14 & 0 & 0 & 0 & 0 & 0 & 0 & 49 \\
\hline C2-1 & 0 & 0 & 0 & 0 & 0 & 0 & 4 & 4 & 5 & 3 & 0 & 0 & 0 & 0 & 0 & 0 & 15 \\
\hline C2-2 & 0 & 0 & 0 & 0 & 0 & 0 & 6 & 22 & 8 & 28 & 0 & 0 & 0 & 0 & 0 & 0 & 63 \\
\hline C2-3 & 0 & 0 & 0 & 0 & 0 & 0 & 6 & 12 & 3 & 10 & 0 & 0 & 0 & 0 & 0 & 0 & 31 \\
\hline C2-4 & 0 & 0 & 0 & 0 & 0 & 0 & 1 & 0 & 1 & 0 & 0 & 0 & 0 & 0 & 0 & 0 & 3 \\
\hline C2-5 & 0 & 0 & 0 & 0 & 0 & 0 & 1 & 4 & 1 & 4 & 0 & 0 & 0 & 0 & 0 & 0 & 10 \\
\hline C2-6 & 0 & 0 & 0 & 0 & 0 & 0 & 12 & 17 & 12 & 14 & 0 & 0 & 0 & 0 & 0 & 0 & 56 \\
\hline C2-7 & 0 & 0 & 0 & 0 & 0 & 7 & 14 & 25 & 15 & 24 & 0 & 0 & 0 & 0 & 0 & 0 & 85 \\
\hline C2-8 & 0 & 0 & 0 & 0 & 0 & 0 & 1 & 11 & 2 & 15 & 0 & 0 & 0 & 0 & 0 & 0 & 29 \\
\hline C2-9 & 0 & 0 & 0 & 0 & 0 & 0 & 27 & 2 & 21 & 1 & 0 & 0 & 0 & 0 & 0 & 0 & 52 \\
\hline C2-10 & 0 & 0 & 0 & 0 & 0 & 0 & 14 & 25 & 11 & 23 & 0 & 0 & 0 & 0 & 0 & 0 & 73 \\
\hline C2-11 & 0 & 0 & 0 & 0 & 0 & 0 & 3 & 7 & 4 & 8 & 0 & 0 & 0 & 0 & 0 & 0 & 22 \\
\hline C2-12 & 0 & 0 & 0 & 0 & 0 & 0 & 194 & 161 & 205 & 253 & 0 & 0 & 0 & 0 & 0 & 0 & 813 \\
\hline C2-13 & 0 & 0 & 0 & 0 & 0 & 0 & 0 & 0 & 0 & 0 & 0 & 0 & 0 & 0 & 0 & 0 & 0 \\
\hline C2-14 & 0 & 0 & 0 & 0 & 0 & 0 & 3 & 4 & 2 & 1 & 0 & 0 & 0 & 0 & 0 & 0 & 11 \\
\hline C2-15 & 0 & 0 & 0 & 0 & 0 & 0 & 3 & 3 & 2 & 0 & 0 & 0 & 0 & 0 & 0 & 0 & 8 \\
\hline C2-16 & 0 & 0 & 0 & 0 & 0 & 0 & 3 & 5 & 1 & 2 & 0 & 0 & 0 & 0 & 0 & 0 & 11 \\
\hline C2-17 & 0 & 0 & 0 & 0 & 0 & 0 & 5 & 8 & 4 & 4 & 0 & 0 & 0 & 0 & 0 & 0 & 21 \\
\hline C2-18 & 0 & 0 & 0 & 0 & 0 & 0 & 10 & 15 & 8 & 19 & 0 & 0 & 0 & 0 & 0 & 0 & 51 \\
\hline C2-19 & 0 & 0 & 0 & 0 & 0 & 0 & 10 & 4 & 6 & 1 & 0 & 0 & 0 & 0 & 0 & 0 & 20 \\
\hline C2-20 & 0 & 0 & 0 & 0 & 0 & 0 & 10 & 3 & 6 & 0 & 0 & 0 & 0 & 0 & 0 & 0 & 19 \\
\hline C2-21 & 0 & 0 & 0 & 0 & 0 & 0 & 5 & 12 & 7 & 18 & 0 & 0 & 0 & 0 & 0 & 0 & 42 \\
\hline C2-22 & 0 & 0 & 0 & 0 & 0 & 0 & 13 & 23 & 12 & 26 & 0 & 0 & 0 & 0 & 0 & 0 & 73 \\
\hline C2-23 & 0 & 0 & 0 & 0 & 0 & 0 & 16 & 15 & 13 & 6 & 0 & 0 & 0 & 0 & 0 & 0 & 51 \\
\hline C2-24 & 0 & 0 & 0 & 0 & 0 & 0 & 8 & 4 & 7 & 1 & 0 & 0 & 0 & 0 & 0 & 0 & 21 \\
\hline C2-25 & 0 & 0 & 0 & 0 & 0 & 0 & 0 & 0 & 0 & 0 & 0 & 0 & 0 & 0 & 0 & 0 & 0 \\
\hline C2-26 & 0 & 0 & 0 & 0 & 0 & 0 & 1 & 4 & 2 & 9 & 0 & 0 & 0 & 0 & 0 & 0 & 16 \\
\hline C2-27 & 0 & 0 & 0 & 0 & 0 & 0 & 1 & 0 & 1 & 0 & 0 & 0 & 0 & 0 & 0 & 0 & 2 \\
\hline
\end{tabular}




\section{LC-ESI-MS-MS transitions}

\begin{tabular}{ccccc}
\hline $\begin{array}{c}\text { pyrrolizidine } \\
\text { alkaloid }\end{array}$ & $\begin{array}{c}\text { parent- } \\
\text { ion }[\mathrm{m} / \mathrm{z}]\end{array}$ & $\begin{array}{c}\text { collision- } \\
\text { energy }\end{array}$ & $\begin{array}{c}\text { fragment- } \\
\text { ions [m/z] }\end{array}$ & $\begin{array}{c}\mathrm{Rt} \\
{[\mathrm{min}]}\end{array}$ \\
\hline Isoproturone-d6 & $213.0[\mathrm{M}+\mathrm{H}]^{+}$ & $18 \%$ & $78+171$ & 11.61 \\
Monocrotaline & $325.8[\mathrm{M}+\mathrm{H}]^{+}$ & $36 \%$ & $120+121+94+194$ & 4.99 \\
Monocrotaline- $N$-oxide & $341.8[\mathrm{M}+\mathrm{H}]^{+}$ & $38 \%$ & $94+118+120+136+236$ & 5.98 \\
Echimidine & $398.1[\mathrm{M}+\mathrm{H}]^{+}$ & $22 \%$ & $120+220+336$ & 8.40 \\
Echimidine- $N$-oxide & $414.1[\mathrm{M}+\mathrm{H}]^{+}$ & $30 \%$ & $220+254+352+396$ & 8.58 \\
Heliotrine & $314.1[\mathrm{M}+\mathrm{H}]^{+}$ & $25 \%$ & $120+138.1+156$ & 7.49 \\
Heliotrine- $N$-oxide & $330.1[\mathrm{M}+\mathrm{H}]^{+}$ & $30 \%$ & $138+172+298$ & 7.82 \\
Lasiocarpine & $412.1[\mathrm{M}+\mathrm{H}]^{+}$ & $30 \%$ & $120+220+238+336+394$ & 9.01 \\
Lycopsamine & $300.1[\mathrm{M}+\mathrm{H}]^{+}$ & $30 \%$ & $94+120+138+156$ & 6.42 \\
Lycopsamine- $N$-oxide & $316.1[\mathrm{M}+\mathrm{H}]^{+}$ & $35 \%$ & $94+111+138+155+172$ & 7.05 \\
Retrorsine & $352.0[\mathrm{M}+\mathrm{H}]^{+}$ & $36 \%$ & $94+120+138+220$ & 7.23 \\
Retrorsine- $N$-oxide & $368.0[\mathrm{M}+\mathrm{H}]^{+}$ & $37 \%$ & $94+120+136+138$ & 7.50 \\
Senecionine & $336.1[\mathrm{M}+\mathrm{H}]^{+}$ & $35 \%$ & $120+138+308$ & 7.41 \\
Senecionine- $N$-oxide & $352.1[\mathrm{M}+\mathrm{H}]^{+}$ & $30 \%$ & $118+120+136+220$ & 7.75 \\
Seneciphylline & $334.1[\mathrm{M}+\mathrm{H}]^{+}$ & $35 \%$ & $120+138+151+306$ & 7.97 \\
Seneciphylline- $N$-oxide & $350.1[\mathrm{M}+\mathrm{H}]^{+}$ & $35 \%$ & $118+120+136.1+322$ & 8.32 \\
Senkirkine & $366.1[\mathrm{M}+\mathrm{H}]^{+}$ & $35 \%$ & $122+150+168$ & 8.54
\end{tabular}

Rt: retention time 
SP2000 SPE-modul program

\begin{tabular}{ccccc}
\hline Step-Nr. & Time [min] & V1 & V2 & Pump (mL/min) \\
\hline 1 & 0,00 & 0 & 2 & 0,300 \\
\hline 2 & 0,01 & 0 & 2 & 0,300 \\
\hline 3 & 1,50 & 1 & 1 & 0,300 \\
\hline 4 & 12,50 & 0 & 1 & 0,300 \\
\hline 5 & 13,00 & 0 & 2 & 0,300 \\
\hline 6 & 17,00 & 0 & 2 & 0,300 \\
\hline
\end{tabular}

Valve 1(V1): 0 Sample Application/ Cleanup/ Recondition 1 Elution

Valve 2 (V2): $\quad 1$ Methanol $+1 \% \mathrm{CH}_{3} \mathrm{COOH}(\mathrm{v} / \mathrm{v})$ 2 Water 